Review

\title{
Performance Comparison of Phase Change Materials and Metal-Insulator Transition Materials for Direct Current and Radio Frequency Switching Applications
}

\author{
Protap Mahanta, Mohiuddin Munna and Ronald A. Coutu Jr. * \\ Department of Electrical and Computer Engineering, Marquette University, Milwaukee, WI 53233, USA; \\ protap.mahanta@marquette.edu (P.M.); mohiuddin.munna@marquette.edu (M.M.) \\ * Correspondence: ronald.coutu@marquette.edu; Tel.: +1-414-288-7316
}

Received: 29 March 2018; Accepted: 1 May 2018; Published: 4 May 2018

\begin{abstract}
Advanced understanding of the physics makes phase change materials (PCM) and metal-insulator transition (MIT) materials great candidates for direct current (DC) and radio frequency (RF) switching applications. In the literature, germanium telluride (GeTe), a PCM, and vanadium dioxide $\left(\mathrm{VO}_{2}\right)$, an MIT material have been widely investigated for DC and RF switching applications due to their remarkable contrast in their OFF/ON state resistivity values. In this review, innovations in design, fabrication, and characterization associated with these PCM and MIT material-based RF switches, have been highlighted and critically reviewed from the early stage to the most recent works. We initially report on the growth of PCM and MIT materials and then discuss their DC characteristics. Afterwards, novel design approaches and notable fabrication processes; utilized to improve switching performance; are discussed and reviewed. Finally, a brief vis-á-vis comparison of resistivity, insertion loss, isolation loss, power consumption, RF power handling capability, switching speed, and reliability is provided to compare their performance to radio frequency microelectromechanical systems (RF MEMS) switches; which helps to demonstrate the current state-of-the-art, as well as insight into their potential in future applications.
\end{abstract}

Keywords: phase change materials; metal insulator transition materials; direct current (DC) switching; radio frequency $(\mathrm{RF})$ switching; performance comparison

\section{Introduction}

Wireless communication systems require complex radio frequency (RF) front end modules to enable reconfigurable and multiband operations as RF mobile technology shifts from 4G to 5G technologies. These complex RF modules require RF switching technologies with low insertion loss, high linearity, high isolation, and high reliability [1]. In current cellular telecommunication systems, solid state RF switching devices are ubiquitous and used primarily because of their high reliability and ultra-fast switching speed. However, high nonlinearity, high power consumption, and low power handling capability associated with these devices pave the way for radio frequency microelectromechanical systems (RF MEMS) switches in commercial use [2]. Cut-off frequency $\left(\mathrm{F}_{\mathrm{CO}}=\frac{1}{2 \pi * R_{\text {on }} \mathrm{C}_{\text {off }}}\right.$ which is commonly known as the figure of merit (FOM) for RF switches) [2] for RF MEMS switches are several orders of magnitude higher than solid state devices. Metal-insulator transition (MIT) and phase change materials (PCM)-based RF switches show FOM values in the middle of these devices as shown in Figure 1, with excellent RF performance which cannot be achieved using MEMS or solid-state switches individually. Taking this into account, recently vanadium dioxide $\left(\mathrm{VO}_{2}\right)$ among metal-insulator transition (MIT) materials and germanium telluride (GeTe) among PCM draw attention as potential RF switching materials due to their unique properties when transitioned 
from insulator to metal (amorphous to crystal for PCM) or vice versa at room temperature along with high OFF/ON resistivity ratio. RF switching devices based on these materials demonstrate low insertion loss, high cut-off frequency, fast switching speed, and promising broadband characteristics (compared to RF MEMS switches of the same size). These attributes make these devices promising candidates for future RF circuitry and also satellite applications. In addition, devices that are based on these innovative materials offer complementary metal oxide-semiconductor (CMOS) compatibility and simplified, low cost fabrication processes [3-5].

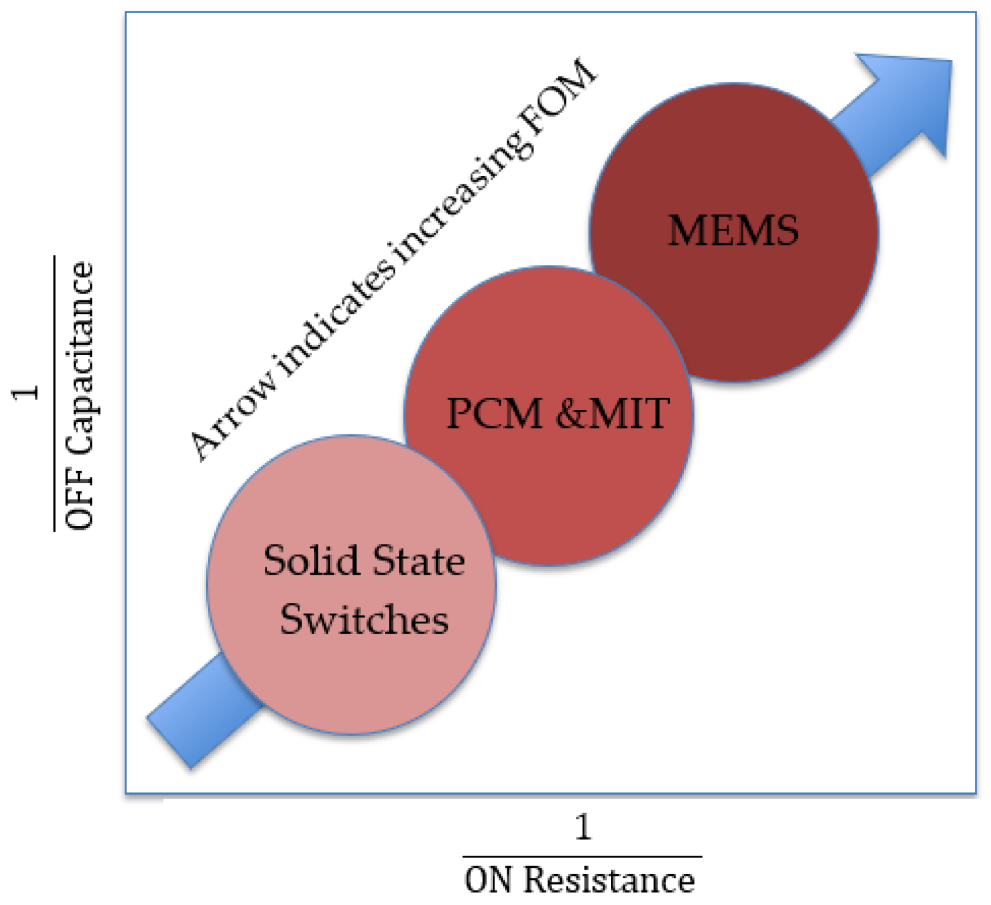

Figure 1. Comparison of figures of merit (FOM) of various radio frequency (RF) switching technologies.

However, the power handling capability of $\mathrm{VO}_{2}$-based devices are relatively low compared to RF MEMS devices. In addition, high power consumption is also a bottleneck for $\mathrm{VO}_{2}$ devices as continuous direct current (DC) power is required during the ON state while PCM-based devices provide a latching ON state where continuous DC power is not required. Lifetime and reliability are still open questions for both types of devices before they can become a commercially viable solution. Moreover, there are many unexplored issues, as well as room for improvements in material growth processes, tuning intrinsic properties, switching mechanisms, and design optimizations when used as a high-performance RF switch.

In this work, we review the experimental studies of $\mathrm{VO}_{2}$ and GeTe-based $\mathrm{RF}$ switches. Initially, we describe the phase transition mechanisms and DC switching characteristic that is common to both devices. An understanding of DC switching behavior is necessary to achieve and evaluate RF performance metrics such as insertion loss, speed, and isolation. Afterwards, device architectures and fabrication methods of the reported works are briefly summarized as these have direct impact on both DC and RF characteristics. We then detail the RF characterizations of the devices demonstrated by various research groups to date. Low insertion loss (less than $\sim 1 \mathrm{~dB}$ ), high signal attenuation with flat wide band response are desired for an acceptable RF switch, applicable in current switching technologies.

We summarize and make a brief vis-a-vis comparison of RF performance parameters between these devices. This will facilitate further study and improve future RF switching devices and present an insight to harness the full potential of these devices for being used in commercial RF applications. 


\section{Review on GeTe and $\mathrm{VO}_{2}$ based $\mathrm{RF}$ Switches}

\subsection{Review on GeTe}

Over the last few decades, phase change materials (PCM) have been extensively used in data storage applications due to their large resistivity contrast between crystalline and amorphous states. Phase changing property of the material was first exploited in 1968 for random access memory applications. In 1978 [6], Burroughs Corporation demonstrated the laser induced switching on $\mathrm{Te}_{81} \mathrm{Ge}_{15} \mathrm{Sb}_{2} \mathrm{~S}_{2}$ but did not able to commercialize due to its slow crystallization and limited cyclability issues. Then in 1987 [7], Yamada et al. brought the breakthrough in optical storage technology by exploring the pseudo-binary alloys ( $\mathrm{GeTe}$ and $\mathrm{Sb}_{2} \mathrm{Te}_{3}$ ) with short crystallization time, improved cyclability and a very high optical contrast. Figure 2 is a ternary phase diagram showing the different possible alloys and the year of discovery and commercialization of PCM in optical storage technology. Since then doped $\mathrm{Sb}_{2} \mathrm{Te}_{3}$ was the prime carrier of all the developments in optical storage technology (from $\mathrm{CD}$ to Blue ray disc).

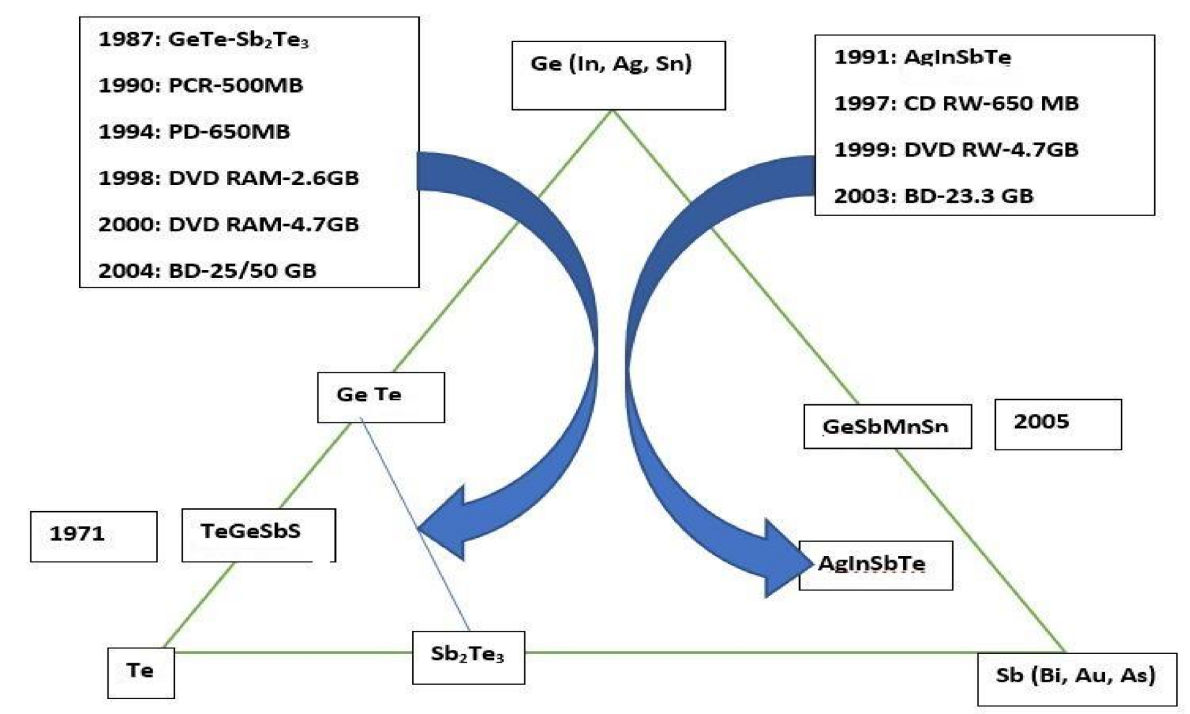

Figure 2. Ternary phase diagram showing the different possible alloys and the year of discovery and commercialization of phase change materials (PCM) in optical storage technology.

Apart from the optical storage applications, a large contrast in resistivity values between amorphous and crystalline states along with the ability to switch reversibly and repeatedly make the PCM a potential candidate for radio-frequency (RF) switching applications. Phase change materials from $\mathrm{Ge}_{\mathrm{x}} \mathrm{Sb}_{\mathrm{y}} \mathrm{Te}_{\mathrm{z}}$ (GST) alloys did not draw much attention for RF switching applications because of their poor thermal stability in an amorphous state and void formation in the crystal structure. However, GeTe, one of the stoichiometric compositions of GST, is mostly investigated for RF switching applications due to its better thermal stability in amorphous state, fast reversible phase transition and high contrast in resistivity ratio. As phase transition nature of these PCM dictates the RF performance, a detailed understanding of this mechanism is critical to optimize RF performance for future telecommunication applications.

\subsubsection{Phase Transition Mechanism and DC Characteristics}

Most of the PCM possess two states namely amorphous and crystalline states at room temperature. The transition between these two states is accomplished through thermal actuation method which includes specific pattern of heating and cooling process [8]. An illustration on phase transition mechanism is depicted in Figure 3. 


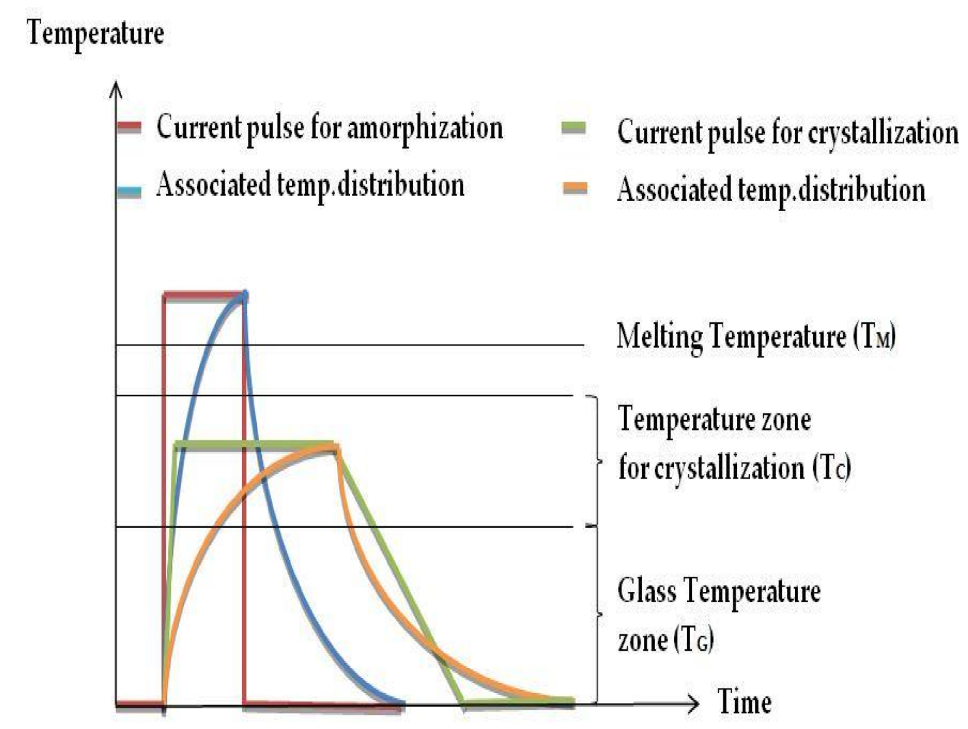

(a)

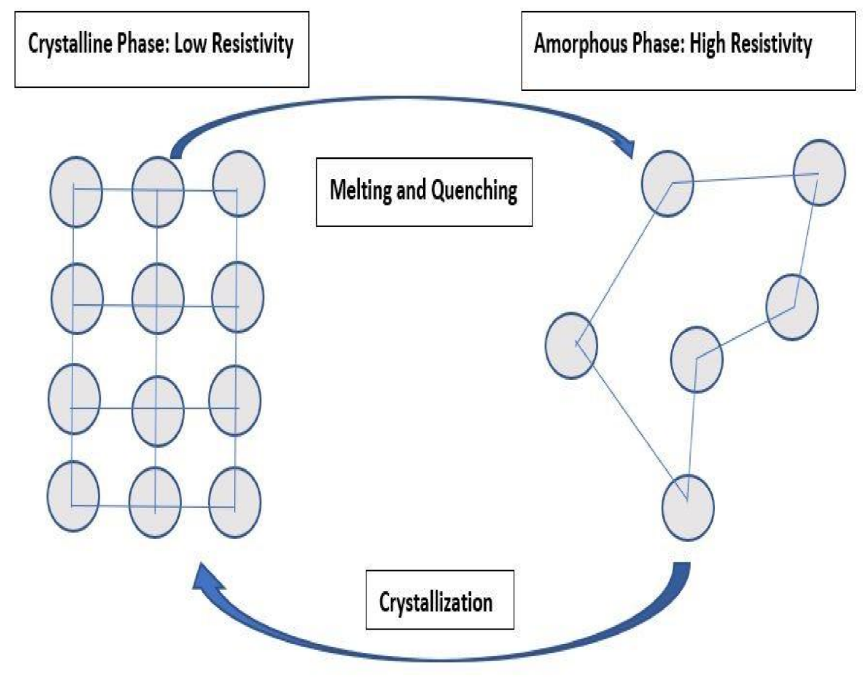

(b)

Figure 3. Illustration of the phase transition mechanisms associated with germanium telluride (GeTe) materials. (a) Required current pulses and resulting temperature profiles for phase change; (b) Crystal structure during phase change.

The phase transition characteristics can be explained through the amorphization and crystallization process $[9,10]$. In the amorphization process, the material is heated up beyond its melting temperature $\left(T_{M}\right)$ first and then a rapid quenching process is involved to convert it into the amorphous state. On the other hand, crystallization process is obtained through heating up the material up to its crystallization temperature $\left(T_{C}\right)$ followed by slow quenching process so that the nucleation and crystalline growth are enabled. The thermal actuation methods for the phase transition can be obtained through direct heating as well as through indirect heating. In direct heating, phase transition mechanism is obtained through the Joule heating approach whereas in the indirect heating, a separate layer of dielectric material is added in switching structure to transfer 
the heat into the PCM. Nonetheless, the thermal actuation method should be implemented with minimal impact on surrounding dielectrics and electrode materials.

In the works of [10-12], it has been reported and confirmed that the contrast in resistivity ratio value of a thin film GeTe varies from $~$ four to six orders of magnitudes over a very narrow temperature window $\left(\sim 175^{\circ} \mathrm{C}\right.$ to $\left.225^{\circ} \mathrm{C}\right)$ upon heating. It has also been reported that the order of magnitude may vary with the film quality, GeTe compositions and nucleation site formation [13]. This distinguishable crystalline and amorphous phase transition in GeTe material is due to their distorted cubic crystal structure with resonant bonding behavior and most of the optical and electrical properties have been explained on the light of this theory in literature [8-10]. The crystal structure of GeTe is formed by $\mathrm{Ge}$ and $\mathrm{Te}$ atoms arranged in a rhombohedrally distorted rock salt-type structure that forms a face-centered cubic (FCC) sub lattice at room temperature.

Along with the high OFF/ON resistivity ratio; phase transformation time, crystallization temperature, phase transformation reproducibility, and geometry of the devices are the key parameters for PCM to be used suitably in RF applications [14]. Crystallization time refers to the time required for the atoms to be arranged in a most favorable long-range order and should be as short as possible for high-speed mobile and random memory applications. To keep the GeTe in amorphous state, crystallization temperature should be in the range of $150{ }^{\circ} \mathrm{C}$ to $200^{\circ} \mathrm{C}$, and to be compatible with Joule heating at a low voltage, the melting temperature should be in the range of $500{ }^{\circ} \mathrm{C}$ to $1000{ }^{\circ} \mathrm{C}$.

\subsubsection{GeTe Growth Process}

The performance of the GeTe based RF switching devices primarily depends on the quality of the deposited film on top of the substrate. The process parameters that influence the film properties include seed layer structure, precursor composition, deposition temperature, pressure, gas flow rates, precursor bubbling temperatures and the substrates. In the literature [15-22], DC sputtering, RF sputtering, Inductively-coupled plasma assisted sputtering, E-beam evaporation, Sol-gel coating, Atmospheric Pressure Chemical Vapor Deposition (APCVD), Metalorganic Chemical Vapor Deposition (MOCVD), Pulsed Laser Deposition (PLD), and Ion Beam Deposition methods have been exploited to deposit the thin film of PCM by different research groups. However, the deposition methods only related to the thin film GeTe are briefly discussed and reviewed in the following paragraphs.

In [15], they formed the active GeTe layer of their RF switch through sputtering process using a Lab 18 Modular Thin Film Deposition System. Good reproducibility, high rates, good scalability and good uniformity were the main reasons for adopting this process. In addition, this method facilitates to deposit film of variable compositions with the use of alloy targets or co-sputtering. However, this method is not effective for the technology which requires vias and trenches due to its lack of conformity and directionality. In [16], collimated sputtering or ionized vapor method has been proposed and exploited to overcome these issues.

In [17], pulsed laser deposition technique has been employed to deposit the GeTe thin film. In this method, high quality films can be grown in a very short time. Various composition as well as stoichiometric transfer of a target material is possible. This method includes a simple vacuum system and is completely decoupled from the laser beam source. In addition to these, it enables precise control of the growth rate. However, in [18] the authors point out that this method has some issues with "splashing" or the particulates deposition on the films due to the sub-surface boiling, expulsion of the liquid layer by shockwave recoil pressure and exfoliation. Narrow angular distribution of the ablated species due to the adiabatic expansion of laser, produced plasma plume and the pitting on the target surface.

Authors in [19-22], have utilized the Chemical Vapor Deposition (CVD) method to deposit the GeTe thin film. This is a very conformal deposition technique. It requires lower substrate temperature and compatible with complementary metal oxide-semiconductor (CMOS) technology. However, requirements of special precursor materials and safety issues e.g., toxic, pyrophoric, or corrosive properties, prevented the method to be widely used in the RF switch fabrication. 


\subsubsection{Device Fabrication and RF Characteristics}

In this section of the paper, we discuss notable device architectures, thermal actuation methods, material selections for heating and isolation, fabrication methods and their associated RF performance, from the early stage to present time. Any recent relevant publications not mentioned in this paper do not decline their contribution to this field.

One of the early novel research on PCM based indirectly heated RF switch using a standard $180 \mathrm{~nm}$ CMOS technology was reported in [23]. In their device architecture, $\mathrm{Ge}_{2} \mathrm{Sb}_{2} \mathrm{Te}_{5}$ (germanium-antimony-telluride) via structure with diameters approximately $200-280 \mathrm{~nm}$ was exploited as switching element. Indirect thermal actuation part was implemented by doped tantalum nitride (TaN). To protect material diffusion into the switching structure, titanium nitride (TiN) was used. The authors report that their device exhibited stable and repetitive phase transition up to 100 switching cycles along with an OFF/ON resistance ratio of approximately 400. Although the authors demonstrated a proof of concept device; the high $\mathrm{ON}$ resistance (approximately $6 \mathrm{~K} \Omega$ ) due to material's high crystalline state resistivity and low reliability limited further investigation into switching applications.

In [24], Bain et al. employed germanium antimony $\left(\mathrm{Ge}_{50} \mathrm{Sb}_{50}\right)$ material composition as switching for the realization of a three-terminal probe reconfigurable RF switch. They designed their novel prototype device using a parallel array of sub-vias; to achieve the reduced size vias along with the optimal current for heating. They did DC magnetron sputtering to deposit $\mathrm{Ge}_{50} \mathrm{Sb}_{50}$ (thickness $\sim 100 \mathrm{~nm}$ ), copper $(\mathrm{Cu})$ (thickness $\sim 500 \mathrm{~nm}$ ) and titanium-tungsten (thickness $\sim 20 \mathrm{~nm}$ ); lift-off to pattern copper $(\mathrm{Cu})$ and reactive ion etching (RIE) to open vias in the structure respectively. The $20 \mathrm{~nm}$ layer of TiW was used as an adhesion, as well as a passivation layer at bottom and top, respectively. They found their device was stable up to 70 phase transitions with the ON resistance approximately $50 \Omega$. Even though the dynamic range and optimized heating current level of their novel switch structure is satisfactory for some RF applications but still this high ON resistance of the device, restricts the device structure and material compositions, to be widely used in RF applications as insertion loss is directly related to it. Moreover, the patterning of $500 \mathrm{~nm}$ vias was implemented through E-beam lithography which adds extra cost with process complexity.

Later in [25], Bain et al. designed and fabricated their RF switch using GeTe material. In this device, they deposited a $100 \mathrm{~nm}$ thick layer of GeTe via with the diameter of 1 micrometer. Authors tuned the resistance of the GeTe via and achieved the high dynamic range through the controlling of deposition conditions. It has been reported that the OFF state resistivity can be reduced at higher sputtering power. They used a $500 \mathrm{~nm}$ layer of copper $(\mathrm{Cu})$ metal for the top and bottom electrodes instead of TiW, to minimize the electrode resistance. A silicon dioxide $\left(\mathrm{SiO}_{2)}\right.$ layer was patterned by etching to define the electrode area. They have observed that their device is able to exhibit $180 \Omega \mathrm{ON}$ resistance and a large dynamic range approximately $7 \times 10^{3}$ due to the lower crystalline state resistivity of GeTe. In addition, they have modeled a relation between ON state resistance and RESET current and reported that the lower reset current can be achieved by choosing a material with lower melting point and a structure with better thermal isolation. Although their device showed improved performance in terms of ON resistance and dynamic range with the new material composition, however, still the reliability, switching speed and insertion loss were not up to the level of the existing switching technology. Since then enormous efforts have been put to improve the material composition quality together with device architecture optimization.

Shim et al. proposed a two terminal directly heated RF Ohmic switch as shown in Figure 4 using $\mathrm{Ge}_{50} \mathrm{Te}_{50}$ in [26]. They fabricated their switching architecture on a passivated Si substrate. They have patterned all the metal connections using a lift-off technique and then deposited the $\mathrm{Ge}_{50} \mathrm{Te}_{50}$ and oxide layer with sputtering and plasma enhanced chemical vapor deposition (PECVD), respectively. They exploited the same two terminals structure for RF signal transmission as well as for thermal actuation. A single layer of $\mathrm{Ge}_{50} \mathrm{Te}_{50}$ via switching structure has been attempted at the beginning of the work but due to its poor performance in terms of $\mathrm{ON}$ resistance and dynamic range, 
an alternative structure with multiple $\mathrm{Ge}_{50} \mathrm{Te}_{50}$ vias has been proposed. This structure serves the purpose of both having a reduced size $\mathrm{Ge}_{50} \mathrm{Te}_{50}$ via for better isolation and larger effective area of the device for fast switching speed. Authors have reported that the multiple GeTe via structure is able to exhibit the $\mathrm{ON}$ resistance approximately $0.6 \Omega$, insertion loss $0.66 \mathrm{~dB}$ at $10 \mathrm{GHz}$, isolation $21 \mathrm{~dB}$ at $10 \mathrm{GHz}$, third order intercept point $>27 \mathrm{dBm}$, dynamic range approximately $10^{5}$ and switching speed approximately $20 \mu \mathrm{s}$. This novel work showed that the multiple $\mathrm{Ge}_{50} \mathrm{Te}_{50}$ via structure is quite functional for switching applications; however, it increases the OFF state capacitance and switching power. Moreover, the reliability and simultaneous action of RF signal transmission and thermal actuation using the same two terminals are also big challenges for this sort of device architecture. Because a switching device is required to have a low resistive path for signal transmission and high resistance path for thermal actuation which is quite difficult to have simultaneously.

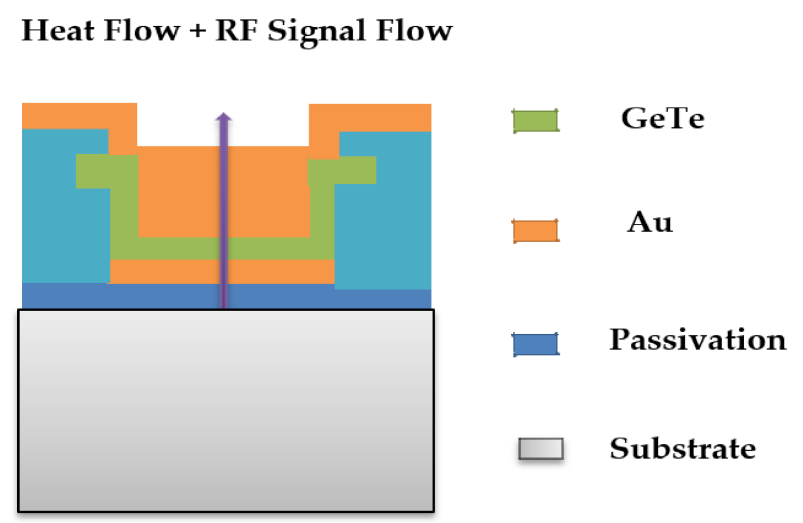

Figure 4. Device layout for a two terminal directly heated GeTe based RF switch.

In [27], to deal with the problems of two terminal device architecture, a novel four terminal indirectly heated inline GeTe based switching structure has been proposed as shown in Figure 5 . In their device, a layer of $75 \mathrm{~nm}$ amorphous GeTe material was deposited through sputtering and a $120 \mathrm{~nm}$ thin film resistor (TFR) made of NiCrSi was patterned through lift off techniques to thermally actuate this GeTe structure. A $30 \mathrm{~nm}$ PECVD deposited electrically insulated barrier of silicon nitride $\left(\mathrm{Si}_{3} \mathrm{~N}_{4}\right)$ material was used to get the better thermal control in phase transition. It has been reported that the device is able to perform ON resistance approximately $4.5 \Omega$, insertion loss $<0.5 \mathrm{~dB}$ at $18 \mathrm{GHz}$, isolation $<9 \mathrm{~dB}$, third order intercept point $>55 \mathrm{dBm}$, dynamic range approximately $10^{5}$ and figure of merit approximately $1 \mathrm{THz}$ for 1500 life cycle.

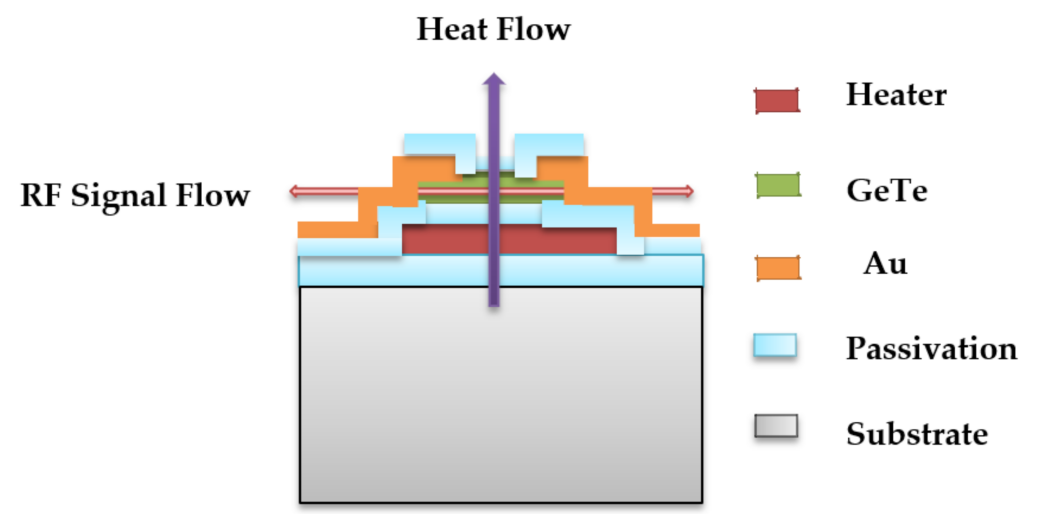

Figure 5. Device layout for a four terminal indirectly heated GeTe based RF switch. 
Later in Reference [28], the authors optimized the deposition parameters, length $(0.9 \mu \mathrm{m}$ to $2.5 \mu \mathrm{m})$ and widths ( $10 \mu \mathrm{m}$ to $30 \mu \mathrm{m})$ of the GeTe film, and the TFR widths ( $0.5 \mu \mathrm{m}$ to $2.5 \mu \mathrm{m})$. It has been demonstrated that the $\mathrm{ON}$ resistance approximately $1.2 \Omega$, insertion loss $<0.3 \mathrm{~dB}$ at $18 \mathrm{GHz}$, isolation $<13 \mathrm{~dB}$, dynamic range approximately $10^{5}$ third order intercept point $>55 \mathrm{dBm}$ and figure of merit approximately $7.3 \mathrm{THz}$ for 10,000 life cycles can easily be achieved with the same architecture with optimized process parameters. In this work, even though this four-terminal indirect heating scheme is able to avoid the isolation problem between DC and RF signal paths, but it is still an unexplored area in determining the effectiveness of heat transfer from the TFR to PCM in indirect manner. Moreover, an independent heating creates a local cold spot at the RF/PCM layer which results an increased-ON resistance and power consumptions. To achieve this increased power requirement, higher current is required to flow at RF/PCM layer which also may reduce the reliability of the device.

In the work [29], Wang et al. presents a four terminal directly heated GeTe based switching structure. A $4 \mu \mathrm{m}$ by $4 \mu$ s witching structure has been fabricated on a Si substrate passivated by aluminum nitride (AlN). In device structure as shown in Figure 6, authors used AlN because of its high thermal conductivity and low loss tangent at higher frequency range. The thermal actuation mechanism was implemented through sputtered titanium nitride (TiN). Titanium nitride (TiN) is a metal like ceramic material which exhibits higher resistivity and good thermal stability at high temperature operation. Moreover, to isolate the RF signal electrodes and heater electrodes, GeTe was deposited twice. This novel switching structure demonstrates ON resistance approximately $5 \Omega$, insertion loss $<0.6 \mathrm{~dB}$ at $20 \mathrm{GHz}$, isolation approximately $20 \mathrm{~dB}$ at $20 \mathrm{GHz}, \mathrm{OFF} / \mathrm{ON}$ resistance ratio approximately $10^{4}$, third order intercept point $>33$ at $2 \mathrm{GHz} \mathrm{dBm}$ and figure of merit approximately $3.7 \mathrm{THz}$. Although this device structure offers higher power handling capability with low ON resistance, however, the requirements for fine lithography and alignment between layers add complicacy in the fabrication process than other contemporary structures.

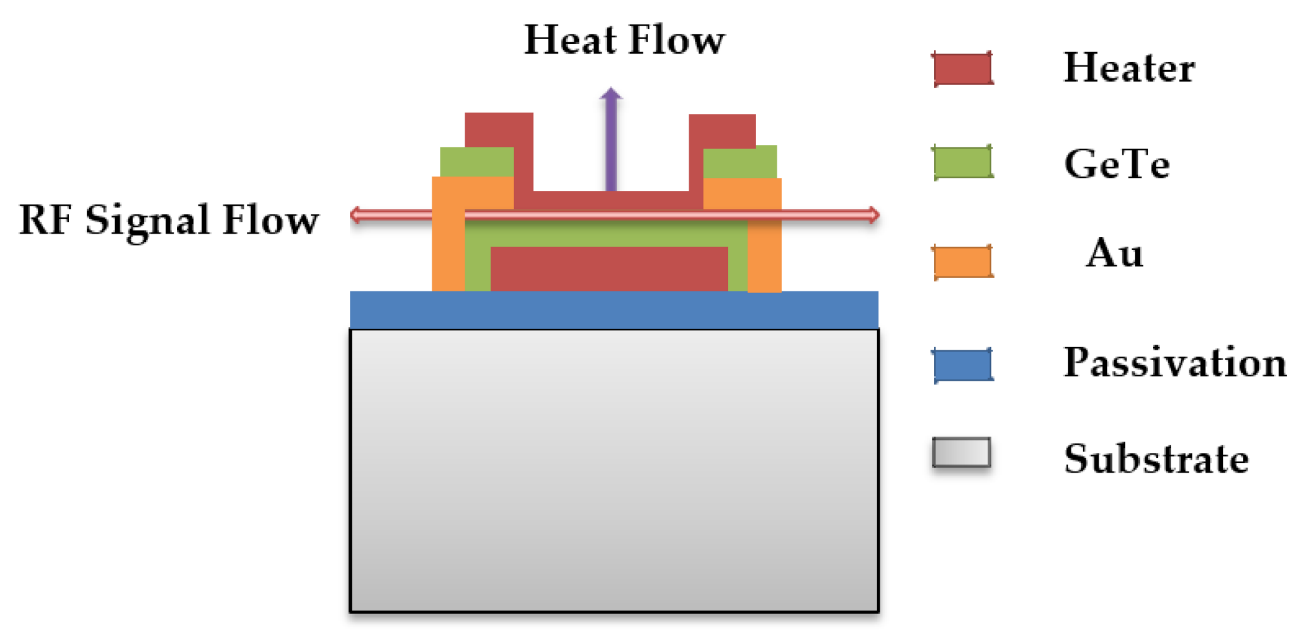

Figure 6. Device layout for a four terminal directly heated GeTe based RF switch.

In [30], authors optimized their previous [27] device structure and fabrication process to improve the device performance. In their new structure, a vertically connected $250 \mathrm{~nm}$ GeTe layer is deposited through sputtering. Two RF electrodes were separated by $0.6 \mu \mathrm{m}$ and on the both sides of GeTe via, a $0.5 \mu \mathrm{m}$ thick gold $(\mathrm{Au})$ layer with thin titanium (Ti) layers was deposited as diffusion layer barrier. They reported that the new structure exhibits ON resistance approximately $3.9 \Omega$, insertion loss $<0.5 \mathrm{~dB}$ at $20 \mathrm{GHz}$, isolation $>18 \mathrm{~dB}$ at $20 \mathrm{GHz}$, dynamic range approximately $10^{4}$, third order intercept point $>30 \mathrm{dBm}$ and figure of merit approximately $4 \mathrm{THz}$. While optimization of the device structure only improves the RF characteristics, still the reliability is required to improve to outperform the other commercial RF switches. 
In [31], Moon et al. realized a RF switch through both shunt and series structures using GeTe. They devised their structure in a lateral Field effect transistor (FET) configuration instead of mostly used via structure to reduce parasitic loss in the device. They reported that their switches able to demonstrate ON resistance approximately $0.3 \Omega$, insertion loss $<0.1 \mathrm{~dB}$ at $40 \mathrm{GHz}$, isolation approximately $30 \mathrm{~dB}$ at $40 \mathrm{GHz}$, third order intercept point $>50 \mathrm{dBm}$, power handling capability approximately 3-10 W, and contrast in resistance approximately $10^{5}$. Later in Reference [32], the authors fabricated a RF switch with an embedded refractory microheater in series configuration. In this work, they characterize the switching structure with two different widths; $50 \mu \mathrm{m}$ and $150 \mu \mathrm{m}$. They reported the switching structure with channel length of $50 \mathrm{~nm}$ demonstrates $\mathrm{ON}$ resistance approximately $2.4 \Omega$, insertion loss $0.25 \mathrm{~dB}$ at $20 \mathrm{GHz}$, isolation $24 \mathrm{~dB}$ at $20 \mathrm{GHz}$, power handling capability approximately $2.8 \mathrm{~W}$, and FOM $11 \mathrm{THz}$. Moreover, for the first time, authors tested their switching structure for spectral regrowth under Wideband code division multiple Access (W-CDMA) signals and abled to demonstrate harmonic power suppression $>90 \mathrm{dBc}$ at $35 \mathrm{dBm}$.

Ghalem et al. [33] developed a four terminal indirectly heated RF switch by an array of GeTe structre. They deposited $100 \mathrm{~nm}$ thick layer of $\mathrm{Si}_{3} \mathrm{~N}_{4}$ through PECVD as a dielectric layer to serve the purpose of electrical isolation as well as thermal coupling. A layer of molybdenum (Mo) with thickness approximately $200 \mathrm{~nm}$ was deposited by DC Magnetron sputtering; for being used as microheater; to perform thermal actuation. The active GeTe layer was deposited by pulse laser deposition (PLD) method followed by successive patterning of metal contact layers through E-beam evaporation. Initially, authors fabricated a single cell of GeTe switch and able to show ON resistance approximately $36 \Omega$, insertion loss $<3 \mathrm{~dB}$, isolation approximately $22 \mathrm{~dB}$ at $24 \mathrm{GHz}$. Due to poor performance, they modified their switching structure with the array of 8 GeTe cell. They reported their multiple GeTe cell units able to exhibit ON resistance approximately $7 \Omega$, insertion loss approximately $0.8 \mathrm{~dB}$ and isolation approximately $25 \mathrm{~dB}$ at $5 \mathrm{GHz}$. Although, their novel multiple cell structure demonstrates promising RF performance, the structure requires high switching power and increases the OFF-state capacitances as well.

In this work [34], authors have realized their switching structure through a GeTe layer with the dimension approximately $300 \mathrm{~nm}$ (thickness) by $250 \mathrm{~nm}$ (width). They deposited their device active layer through co-pulverized technique which was patterned by RIE technique. Afterwards, a metal layer of Al with thickness of $400 \mathrm{~nm}$ was patterned on top of the $500 \mathrm{~nm}$ oxide layer. They used aluminum instead of gold ( $\mathrm{Au}$ ) to maintain the fabrication compatibility with back end of line (BEOL) technology. The passivation of the device surface was implemented by a $100 \mathrm{~nm}$ nitride layer through PECVD method. Their switching device exhibits ON resistance approximately $1.7 \Omega$, insertion loss $<0.2 \mathrm{~dB}$, isolation $>18 \mathrm{~dB}$ at $40 \mathrm{GHz}$ and dynamic range approximately $1.8 \times 10^{4}$. However, the authors did not report the power handling capability, third order intercept point and most importantly reliability of their switch.

\subsection{Review on $\mathrm{VO}_{2}$}

Transitional metal oxides get considerable interest in electronics and other engineering applications over few decades. These materials show metal insulator transition (MIT) triggered by external stimuli [35-37]. Among all the other MIT materials, $\mathrm{VO}_{2}$ draws most interest because of its unique property of metal insulator transition, which bring sharp change in electronic and optical properties at room temperature, whereas the other material shows phase change far below and above room temperature $[35,38,39]$. Intense study is still going on to understand the underlying physical mechanism responsible for phase transition. It is evident in [38,40-42] that of both peril transition (structural) and mot transition (electronic) are responsible for phase transition. $\mathrm{VO}_{2}$ changes from semiconductor (bandgap approximately $1 \mathrm{eV}$ ) [43] to monoclinic crystal structure to metal with rutile tetragonal structure as temperature increases above $68^{\circ} \mathrm{C}$. 


\subsubsection{Phase Transition Mechanism and DC Characteristics}

Metal insulator transition in $\mathrm{VO}_{2}$ can be triggered in various ways, for example, by thermal heating, electric field accompanied with joule heating, pressure, optical excitation etc. [35,38,44,45] Typical transition characteristics is shown below in Figure 7.

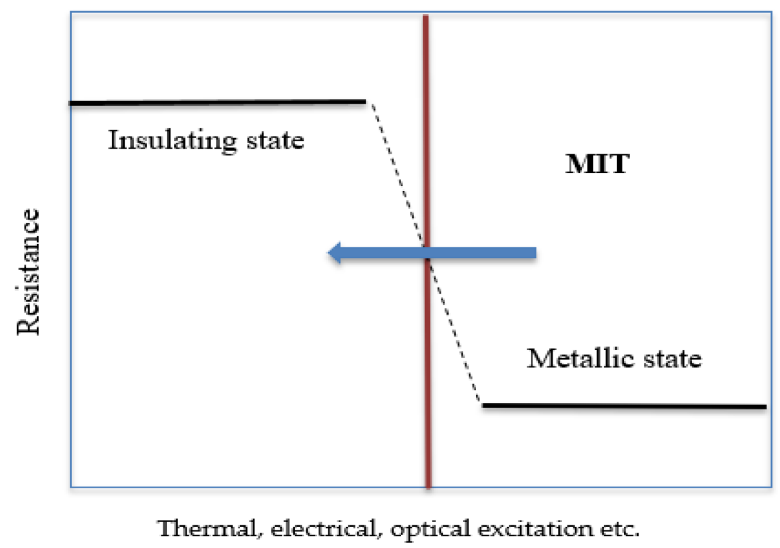

Figure 7. Typical metal-insulator transition characteristic for metal-insulator transition (MIT) materials (i.e., Vanadium Dioxide).

Thermally driven phase transition shows best resistivity contrast $\left(\rho_{\text {OFF }} / \rho_{\text {ON }}\right)$ on the order of $10^{3}$ to $10^{5}$ depending on the quality (crystallinity and sociometry of the film), there is hysteresis in the characteristics with width of $1-5{ }^{\circ} \mathrm{C}[35,38]$. It takes approximately $50 \sim 100 \mathrm{~ns}$ for the transition to occur. In insulating state, $\mathrm{VO}_{2}$ has resistivity in the order of $10^{\circ}$ (one) whereas in metallic state it is on the order of $10^{-4}$ [38].

On the other hand, electrically driven phase transition is much faster and typically in the order of few nanoseconds. However, in this case the OFF/ON resistivity contrast is one or two orders of magnitude lower (from $10^{2}$ to $10^{3}$ ) [46]. There are several works have been done on two terminals and three terminal devices. In two terminal devices, as applied voltage increases $\mathrm{VO}_{2}$ goes from high resistive state to low resistive metallic states. It is demonstrated that only joule heating cannot make such a fast transition, both electric field in the order of $10^{4}$ to $10^{5} \mathrm{~V} / \mathrm{cm}$ [47] and joule heating drives the phase transitions. In this case filamentary conduction may occurs (percolation mechanism) through the $\mathrm{VO}_{2}$ material, which suppress full volume switching leads to lower resistivity contrast [48]. To protect the device from overheating current compliance (limits the current in on state) external series resistances are needed. In micron scale, DC characteristic show S-type IV curve, which corresponds to negative differential resistance (NDR). Several steps jump in current may occur before a sharp big jump, due to partial transitions [49]. The voltage (typically several volts for micron scale devices) needs to make the transition depends on various factors such as geometry of the device, ambient temperature, thermal conductivity of the substrate etc. As temperature increases transition voltage decreases. The hysteresis width, resistivity contrast and switching speeds depend on the quality of the materials (stoichiometry and crystalline quality). Transient response of $\mathrm{VO}_{2}$ devices show voltage or current induced self-oscillation which is attributed to parasitic capacitance etc. Amplitude and frequency of this oscillation depend on various factors, such as applied voltage, temperature etc.

\subsubsection{Growth and Fabrications}

Growth of homogeneous and high quality $\mathrm{VO}_{2}$ is a challenge as it contains various valence state which leads to various oxides phases, namely $\mathrm{VO}, \mathrm{V}_{2} \mathrm{O}_{3}, \mathrm{VO}_{2}, \mathrm{~V}_{2} \mathrm{O}_{5}$ etc. with varying $\mathrm{V} / \mathrm{O}$ ratios [50]. So, very subtle growth parameter optimization is needed. Within a narrow window of growth parameters stoichiometric $\mathrm{VO}_{2}$ growth with good crystallinity is possible. Various growth techniques such as magnetron sputtering, pulse laser deposition (PLD), CVD, sol-gel, electron beam evaporation 
etc. $[39,48,50,51]$ have been used for thin films growth of $\mathrm{VO}_{2}$. Thin film has been deposited on various substrates to achieve varying quality of films and suitable for various applications such as glass, $\mathrm{Si}$, $\mathrm{SiO}_{2} / \mathrm{Si}$, sapphire, transparent conductive substrate like indium tin oxide, $\mathrm{GaN}$, flexible substrate like polyethylene terephthalate (PET), muscovite etc. [39]. Crystallinity and lattice mismatch of the substrate affect the quality of film which directly affect the resistivity contrast. For example, $\mathrm{VO}_{2}$ grown on C-cut sapphire have good crystalline quality with resistivity contrast in the order of three to four as sapphire has good lattice match with $\mathrm{VO}_{2}$ [51]. On the other hand, resistivity ratio for a film grown on $\mathrm{Si}$ or $\mathrm{SiO}_{2} / \mathrm{Si}$ substrate shows poor crystalline quality which is attributed to the amorphous nature of the substrate [52]. Resistivity contrast of the film also varies with deposition technique and on film thickness and choice of substrates [53,54]. $\mathrm{VO}_{2}$ film grown on C-cut sapphire by PLD shows resistivity contrast higher than $10^{3}$ with film thickness as low as $20 \mathrm{~nm}$ [55]. This is why PLD is very popular technique for growing $\mathrm{VO}_{2}$ film. Interfacial strain and doping of $\mathrm{VO}_{2}$ with $\mathrm{Al}, \mathrm{W}$ etc. also alter the properties (electronic, optical and transition temperature, hysteresis width, sharpness of transition etc.) of $\mathrm{VO}_{2}$ film, which give additional degrees of freedom to engineer the material properties suitable for specific applications.

\subsubsection{Device Fabrication and RF Characteristics}

Vanadium dioxide-based RF devices get considerable attention only for a decade, although there are handful of work in early 1990s [56,57]. The first reported work on $\mathrm{VO}_{2}$ based RF switches is done by Sovero et al. [56]. They demonstrated $\mathrm{VO}_{2}$ based RF switches on $\mathrm{Si}_{3} \mathrm{~N}_{4} / \mathrm{GaAs}$ (Gallium arsenide) substrate triggered by on chip heater with $30 \mathrm{~mW}$ of power. They achieved fast (switching time $30 \mathrm{~ns}$ ) and broadband RF response with insertion loss less than $1 \mathrm{~dB}$ and attenuation of more than $12 \mathrm{~dB}$ up to $40 \mathrm{GHz}$. However, interest on $\mathrm{VO}_{2}$ based device did not grow much as it needed on chip integrated heater for thermal triggering. Recently, interest on $\mathrm{VO}_{2}$-based devices has drawn attention as fast electrically driven phase transitions are demonstrated by various research groups $[38,58]$. Taking this into account, Dragoman et al. [59] simulated a $\mathrm{VO}_{2}$ based series type Co-Planer Waveguide (CPW) device. Their simulation shows that $2 \mu \mathrm{m}$ thick $\mathrm{VO}_{2}$ patch in silicon (Si) substrate shows more than $100 \mathrm{~dB}$ modulation in transmission up to $10 \mathrm{GHz}$. A typical $\mathrm{VO}_{2}$ based $\mathrm{RF}$ switching structure is shown in Figure 8.

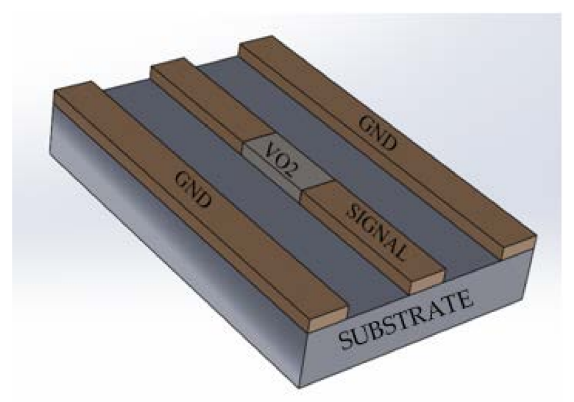

(a)

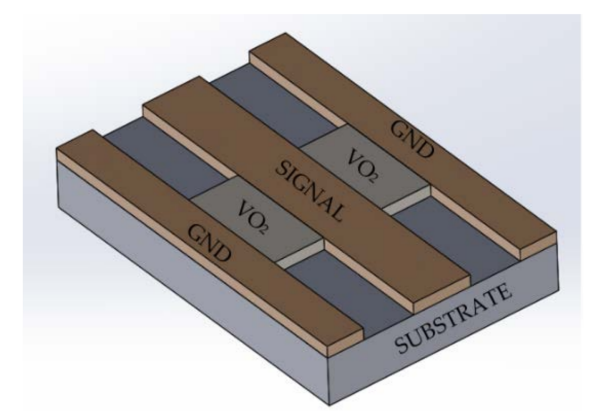

(b)

Figure 8. A generic $\mathrm{VO}_{2}$ Based Co-Planer Waveguide (CPW) RF Switches (a) Series Type (b) Shunt Type.

\section{Thermally Triggered RF Switches}

For $\mathrm{VO}_{2}$ based RF switches, thermally triggered device came earlier than electrically triggered device. Easy implementation, easy testing and high OFF/ON resistivity ratio contrast motivated researcher to work on thermally triggered switches. Blondy et al. developed a $\mathrm{VO}_{2} \mathrm{RF}$ microwave switches on C-cut Sapphire and $\mathrm{SiO}_{2} / \mathrm{Si}$ substrate with thermal activation/triggering using an external heater [60]. They found average isolation of $30-40 \mathrm{~dB}$ in the spectral range of $500 \mathrm{MHz}$ to $35 \mathrm{GHz}$ with insertion loss of $0.8-3 \mathrm{~dB}$. Both Shunt and Series configurations are investigated with active 
switching material length of $1000 \mu \mathrm{m}$ and $500 \mu \mathrm{m}$. A VO ${ }_{2}$ film of $200 \mathrm{~nm}$ has been deposited by PLD from high purity grade $(99.95 \%)$ vanadium $(\mathrm{V})$ metal targets. They obtained pure $\mathrm{VO}_{2}$ stabilized phase without any posttreatment. As there is relatively low lattice mismatch (4.5\%) between $\mathrm{VO}_{2}$ monoclinic phase and sapphire $\left(\mathrm{c}-\mathrm{Al}_{2} \mathrm{O}_{3}\right)$, so this substrate is preferred to deposit mono-oriented $\mathrm{VO}_{2}$ thin films [61]. Indeed, they found monoclinic $\mathrm{VO}_{2}$ on Sapphire Substrates. They found three orders of magnitude change in resistance by thermal activation. On the other hand, film deposited on $1 \mu \mathrm{m}$ $\mathrm{SiO}_{2} / 500 \mu \mathrm{m}$ silicon ( $\mathrm{Si}$ )substrate are found to be orthorhombic structure as in this case the substrate is amorphous. This time resistance contrast $\left(R_{O F F} / R_{O N}\right)$ occurring on MIT is only $10^{2}$. CPWs are made by thermal evaporation of $\sim 200 \mathrm{~nm}$ gold $(\mathrm{Au})$ with signal line width of $100 \mu \mathrm{m}$. After $\mathrm{VO}_{2}$ deposition they thickens the gold $(\mathrm{Au})$ line of $\mathrm{CPW}$ to $800 \mathrm{~nm}$ to minimize propagation loss. Insertion for $\mathrm{VO}_{2}$ for shunt type device (Length $=1000 \mu \mathrm{m}$ ) introduce a low loss of only $\sim 0.8 \mathrm{~dB}$ when it is in semiconducting states (at $300 \mathrm{~K})$. When temperature overpasses transition temperature ( $>341 \mathrm{~K}^{2} \mathrm{VO}_{2}$ film become metallic and signal shorted to ground. Signal attenuated more than $25 \mathrm{~dB}$ up to $12 \mathrm{GHz}$. From 13 to $35 \mathrm{GHz}$ input signal isolation or attenuation loss is higher than $35 \mathrm{~dB}$. The average attenuation in the spectral range of $500 \mathrm{MHz}$ to $35 \mathrm{GHz}$ is $37 \mathrm{~dB}$. They have done the same measurement on series (length $=500 \mu \mathrm{m}$ ) type devices. This device works in opposite way. When the temperature is above transition temperature (e.g., $400 \mathrm{~K}) \mathrm{VO}_{2}$ is in metallic states and $\mathrm{RF}$ signal passes through the signal line with an insertion loss of $\sim 2.5 \mathrm{~dB}$. At room temperature, it is in an insulating state and blocks the RF signal, with an average attenuation/isolation of $40 \mathrm{~dB}$ in the same spectral range. It is clearly evident that series type device has better in terms of signal isolation. In case of $\mathrm{SiO}_{2} / \mathrm{Si}$ substrate the average isolation loss in the same spectral range is $-24 \mathrm{~dB}$ (shunt) and $-25 \mathrm{~dB}$ (series). And insertion loss / transmission loss in approximately $3 \mathrm{~dB}$ for both cases. Devices fabricated on $\mathrm{SiO}_{2} / \mathrm{Si}$ has little poor performance, as $\mathrm{VO}_{2}$ film has poor quality with resistance contrast of one order of magnitude lower than film deposited of C-cut sapphire. Another important thing worth mentioning is that the series type device outperforms shunt type device in terms of isolation characteristics. The same group has done another work on shunt device with same growth and fabrication technique but a modification in the device structure. This time two $250 \mathrm{~nm} \mathrm{VO}$ film patches fill the gap between signal and ground lines of the $\mathrm{CPW}$ structure instead of one continuous patch [60]. $\mathrm{VO}_{2}$ shows three orders of magnitude in resistivity contrast. For $450 \mu \mathrm{m}$ patches, they get insertion loss less than $0.7 \mathrm{~dB}$ and attenuation more than $32 \mathrm{~dB}$ (average attenuation in 40 ) in the spectral range of $100 \mathrm{MHz}$ to $40 \mathrm{GHz}$, which is better than their previous work with twice the length [60]. They also conclude that $\mathrm{VO}_{2}$ length affects both insertion loss and attenuation (more affected), both increases with increasing length.

Very high bandwidth can be achieved by $\mathrm{VO}_{2}$ devices. Hillman et al. use series type configuration but with inverted microstrip lines [62]. Their RF sputtered $600 \mathrm{~nm} \mathrm{VO}_{2}$ film shows sharp thermally triggered transition with $\mathrm{OFF} / \mathrm{ON}\left(\mathrm{R}_{\mathrm{ON}} \sim 1 \Omega\right.$, and $\mathrm{R}_{\mathrm{OFF}}=20 \mathrm{~K} \Omega$ ) contrast of more than $10^{3}$. To switch the device to the on state (switching speed $2 \mu \mathrm{s}$ ), the on chip integrated heater needs $20 \mathrm{~mW}$ of power. They remarkably demonstrated high broadband operation up to $110 \mathrm{GHz}$ with insertion loss less than $0.5 \mathrm{~dB}$ and isolation approaching $15 \mathrm{~dB}$ (up to $50 \mathrm{GHz}$ it is $0.2 \mathrm{~dB}$ and $21.5 \mathrm{~dB}$, respectively). The device shows low off state capacitance which corresponds to cutoff frequency of $\sim 40 \mathrm{THz}$. Furthermore, they developed a parametric switching model with varying the channel length and width. The model predicts that low insertion loss $<1 \mathrm{~dB}$ with isolation of more than $12 \mathrm{~dB}$ can be fabricated up to $220 \mathrm{GHz}$ by utilizing their existing device process.

To implement thermally triggered $\mathrm{VO}_{2}$ switch in practical RF system, on chip integrated heater is needed. Hillman et al. [62] demonstrated inverted microstrip line type device with integrated heater. Pan et al. [63] implemented CPW series type RF device with an integrated heater as shown in Figure 9, the same time of the device was demonstrated earlier with an external heater [60]. Pt heater is fabricated on top of $\mathrm{VO}_{2} \mathrm{CPW}$ structure with silicon dioxide $\left(\mathrm{SiO}_{2}\right)$ as isolation layer. They compared the RF performance between devices with and without integrated heater. $\mathrm{VO}_{2}$ layer was deposited using PLD technique of thickness of $350 \mathrm{~nm}$ and RF characterization was done up to $15 \mathrm{GHz}$. Device without $\mathrm{SiO}_{2}$ and $\mathrm{Pt}$ heaters shows insertion loss less than $4 \mathrm{~dB}$ and isolation greater than $30 \mathrm{~dB}$, whereas after 
integration the Pt heater the insertion and isolation reach $5 \mathrm{~dB}$ and $20 \mathrm{~dB}$ respectively. It shows that in the latter case device performance worsen, $10 \mathrm{~dB}$ degradation in isolation and $6 \mathrm{~dB}$ degradation in return loss. For devices without a heater, $R_{\text {on }}=13 \Omega$ and $C_{\text {off }}$ is $5.8 \mathrm{pF}$ which corresponds to a cut off frequency of $2.1 \mathrm{THz}$. It is evident that incorporating of $\mathrm{SiO}_{2}$ layer degrades device performance although they did not find any structural changes in $\mathrm{VO}_{2}$ layer on XRD measurement. However, earlier growth of $\mathrm{VO}_{2}$ on silicon $(\mathrm{Si})$ or $\mathrm{SiO}_{2} / \mathrm{Si}$ substrate shows that silicide forms in the interface, that degrade the quality of $\mathrm{VO}_{2}$ films itself. Here $\mathrm{SiO}_{2}$ layer is deposited with physically enhanced $\mathrm{CVD}$ at $300{ }^{\circ} \mathrm{C}$. Other low temperature passivation layer instead of $\mathrm{SiO}_{2}$ may help to improve the performance of the devices.

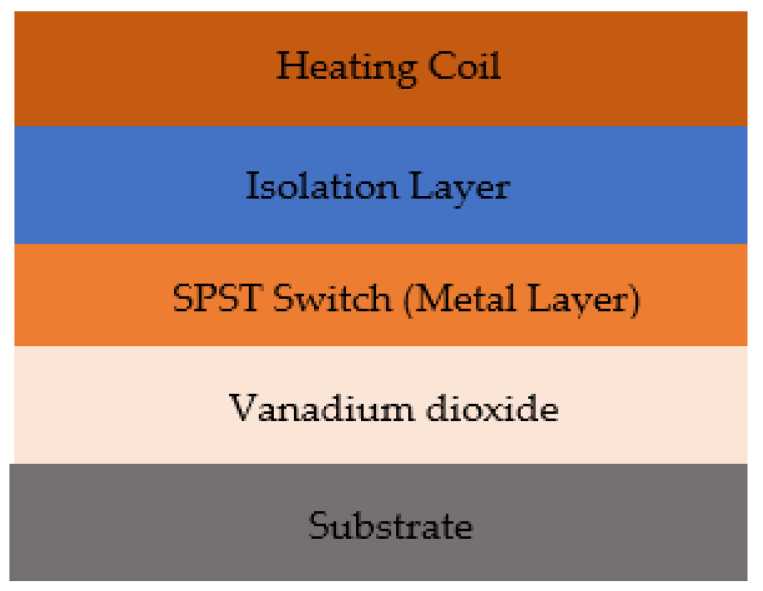

Figure 9. $\mathrm{CPW}$ series type devices with integrated heater and silicon dioxide $\left(\mathrm{SiO}_{2}\right)$ as passivation layer.

Imperfect crystal quality (amorphous, polycrystalline, stoichiometric) suppress the performance $\mathrm{VO}_{2}$ based devices. On the other hand, during MIT single crystalline bulk or epitaxial $\mathrm{VO}_{2}$ has suffered from fracture and degradation of their property due to huge elastic stress, in addition to transition temperature shift bellow room temperature [64-66]. Lee et al. [67] recently demonstrated thermally triggered RF switches using PLD grown $\mathrm{VO}_{2}$ thin film $(300 \mathrm{~nm})$ on $\mathrm{TiO}_{2}(001)$ substrate with $\mathrm{SnO}_{2}$ buffer layer as shown in Figure 10. $\mathrm{SnO}_{2}$ has large ( 4.2\%) lattice mismatch with $\mathrm{VO}_{2}$ which lead to large and abrupt strain relaxation in the interface, this suppress the lattice-stain-induced lowering, broadening of thermally triggered metal-insulator transition (T-MIT) and cracking during MIT $[66,68,69]$ They achieve crack free film with homogeneous bulk like lattice with sharp electrically triggered MIT (E-MIT) with OFF/ON contrast of $10^{4}$ [53]. They analyzed their CPW shunt type (normally on) device in the frequency range of $45 \mathrm{MHz}$ to $40 \mathrm{GHz}$ and found that device property remains unchanged over $10^{3}$ repeated thermal cycle with isolation more than $15 \mathrm{~dB}$ for entire spectral range and insertion loss les that $3 \mathrm{~dB}$ up to $24.2 \mathrm{GHz}$. They found a sharp transition in insertion loss at 60 and $66^{\circ} \mathrm{C}$ during cooling and heating respectively (within $<3{ }^{\circ} \mathrm{C}$ up to $24.2 \mathrm{GHz}$ ) with a low insertion loss of $-1.36 \mathrm{~dB}$ and isolation of $17.56 \mathrm{~dB}$ at $12.03 \mathrm{GHz}$, respectively. Which indicates low power consumptions as hysteresis loop gap is only $6^{\circ} \mathrm{C}$. The measured average group delay is $2.49 \mathrm{ps}$ - this small group delay indicates low phase distortion of the signal over a broad spectral range, suitable for ku-band RF switches. At ku band frequencies $(12,15,18 \mathrm{GHz})$ with input power $1 \mu \mathrm{W}$ to $2 \mathrm{~mW}$ devices shows linear RF power characteristics. Optimizing the design before fabrication by advanced design system (ADS) and extracting the lumped parameter model they found the cut off frequency as $18.9 \mathrm{THz}\left(\mathrm{R}_{\mathrm{on}}=1.2 \Omega\right.$ and $\left.\mathrm{C}_{\mathrm{off}}=7 \mathrm{fF}\right)$ which is higher than that of typical p-i-n diodes, FET switches, and PCM switches. 


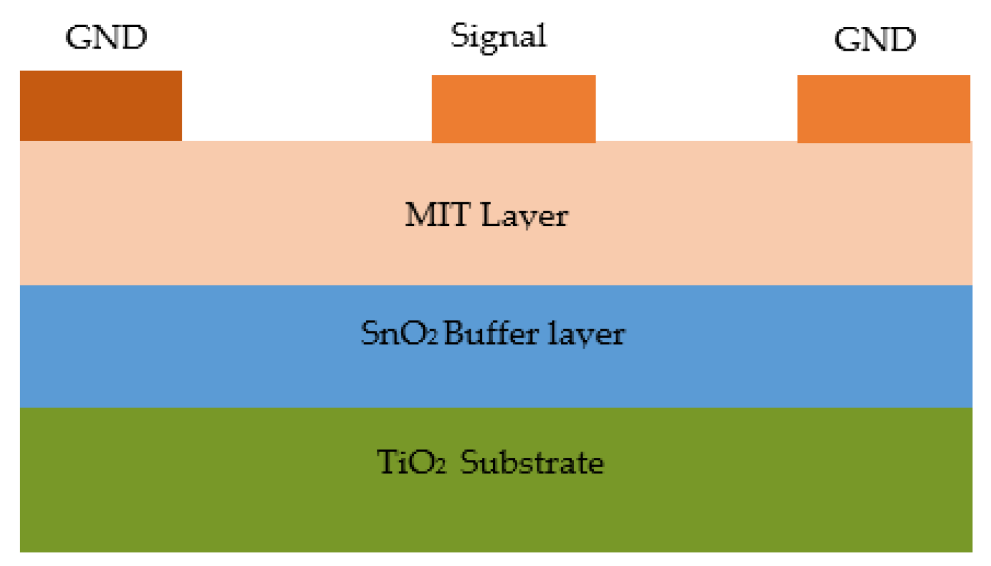

Figure 10. Schematic of epitaxial $\mathrm{VO}_{2}$ based $\mathrm{RF}$ switches grown on $\mathrm{SnO}_{2} / \mathrm{TiO}_{2}$ (001) substrate.

\section{Electrically Triggered RF Switches}

Electrical switching (E-MIT) in $\mathrm{VO}_{2}$ is much faster $[38,58,60,70]$ and comparatively easier to implement, as no additional heating element is needed. Electrical switching is occurred by joule heating coupled with carrier injection [53]. Crunteanu et al. [71] first demonstrated electrically controlled $\mathrm{VO}_{2}$ based RF-switches. They analyzed CPW series type device in both voltage and current controlled mode. This work present methodical investigation of the reliably and lifetime of the RF device, which was rarely done before. Previous work reported that after only approximately 100 thermal cycles amorphous $\mathrm{VO}_{2}[72,73]$ faces rapid degradation in material properties. Ko and Ramanathan [67] suggested that polycrystalline $\mathrm{VO}_{2}$ thin films prevent microcrack formation and also suppress oxygen diffusion to oxygen deficient regions from $\mathrm{VO}_{2}$ clusters, as happens in amorphous film. $\mathrm{VO}_{2}$ thin film were deposited using reactive PLD and they found five orders of magnitude change in resistivity by thermally induced MIT for $200 \mathrm{~nm}$ thin film. They examined I-V characteristics in both voltage and current controlled mode. Hysteresis for V-mode is higher than that of I-mode, which indicate more joule heating. For $10-\mu \mathrm{m}$ long devices they found isolation of more than $15 \mathrm{~dB}$ in the spectral range of $100 \mathrm{MHz}$ to $25 \mathrm{GHz}$ and insertion loss of $3 \mathrm{~dB}$ with bias voltage of $20 \mathrm{~V}$. Finally, they investigated the change in properties during cyclic activation $\mathrm{VO}_{2}$ devices in $\mathrm{N}_{2}$ atmosphere. They modulated $10 \mathrm{GHz}$ RF signal ( $20 \mathrm{~dB}$ difference transmission between ON and OFF state) with triangular pulses, and activation/triggering voltage of the device $\mathrm{V}_{\mathrm{ACT}-\mathrm{ON}}$ as performance parameter. After 16.25 million activation cycles, $\mathrm{V}_{\mathrm{ACT}-\mathrm{ON}}$ voltage suddenly drops to zero indicating device failure. In case of current controlled device $10 \mathrm{~mA}$ amplitude triggering pulse is used with $1 \mathrm{kHz}$ frequency and activation current $\mathrm{I}_{\mathrm{ACT}-\mathrm{ON}}$ as a performance parameter. This device can perform more than 260 million cycles without any visible degradation. Overall current controlled device has lifetime 16 times longer than voltage-controlled device. As shown in the I-V measurement, hysteresis is far more pronounced in $\mathrm{V}$-mode operation, which indicate more joule heating in metallic state (current above $45 \mathrm{~mA}$ ). Whereas in I-mode hysteresis is narrower, which indicate less resistive heating, as $\mathrm{VO}_{2}$ become metallic at currents above $5 \mathrm{~mA}$ only. So, there is less thermal and low dielectric stress due to electric fields. But there is current induced self-oscillation in I-mode with depends on amplitude of the activation signal, heat accumulation and value of external series resistance. The amplitude of the oscillation changes in reliability test. This kind of oscillation was previously observed in voltage controlled $\mathrm{VO}_{2}$ switches [70,74].

The speed of RF-switching by E-MIT is similar to the switching of speed of E-MIT itself, which is on the order of few nanoseconds [75,76]. Ha et al. [49] worked on the switching speed of a CPW series $\mathrm{VO}_{2}$ device, as shown in Figure 11, with respect to RF switching applications. In their device, they grew $\mathrm{VO}_{2}$ film of $120 \mathrm{~nm}$ thickness by RF magnetron sputtering with device dimension width $=25 \mu \mathrm{m}$ and length $=5-15 \mu \mathrm{m}$. The change in electrically driven MIT was $\sim 10^{3}$ (full volume switching) which is of same order of thermally driven MIT, which is notably larger than most literature reports with 
similar film thickness and metrology $[60,71,75,77]$. The transient response was examined along with the $2.3 \mathrm{GHz}$ RF signal with $100 \mathrm{~mA}$ compliance current. After several small currents jump a large jump was observed at $3 \mathrm{~V}(\mathrm{t}=21.4 \mu \mathrm{s})$ corresponding to full volume switching, followed by some damped oscillation which is attributed to the capacitive effects with coexisting metallic and insulating phases. The rise time is $\sim 5 \mu \mathrm{m}$ (time between abrupt jump and steady sate values, which is switching time from an RF device perspective), whereas the large abrupt jump takes only $14 \mathrm{~ns}$, it is of the same order as quoted on literature as dc transient switching time $[75,76,78]$. They also found RF-signal insertion loss is a function of bias current. At bias current of 70 to $80 \mathrm{~mA}$, insertion loss is $\sim 2.95 \mathrm{~dB}$ up to $13 \mathrm{GHz}$ whereas isolation is measured as more than $25 \mathrm{~dB}$ up to $13 \mathrm{GHz}$. They also investigate effect of RF-power on the on state and find that RF input power further drives the $\mathrm{VO}_{2}$ into more mellitic states, which suggest that RF triggering of MIT may also possible. For further development of RF device, they simulate the RF-response using both lumped element and 3D electromagnetic model. In lumped signal model, $\mathrm{VO}_{2}$ is modeled as parallel $\mathrm{RC}$ circuit which has current dependent resistance arises from MIT and capacitance arises from dielectric nature of $\mathrm{VO}_{2}$ and proximity coupling of two signal lines. Using resistance and capacitance values as fitting parameters, they found that $R_{\text {on }}$ (on state resistance) equals to $42 \Omega$ and $\mathrm{R}_{\mathrm{OFF}}$ equals to $51 \mathrm{~K} \Omega$ and extracted capacitance is $\sim 0.006 \mathrm{pF}$. They suggested that optimization of device geometry to $75 \mu \mathrm{m}$ by $10 \mu \mathrm{m}$ to reduce the on resistance, can effectively short the capacitance, can reduce insertion loss to $1 \mathrm{~dB}$ with broad band flatness up to $40 \mathrm{GHz}$ in on state. As device length increases parasitic capacitance decreases, so isolation will increase with longer device. Their simulation shows a $3.2 \mathrm{~dB}$ increases in isolation when channel length increases from 5 to $15 \mu \mathrm{m}$, which agrees with measured data.

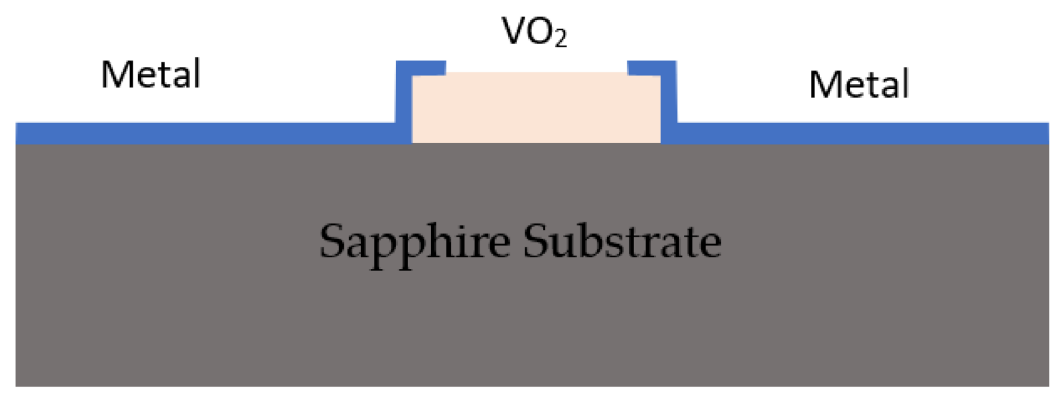

Figure 11. Cross-sectional view of Electrically triggered $\mathrm{VO}_{2}$ based $\mathrm{RF}$ switches.

Most of the $\mathrm{VO}_{2}$ based device RF devices are grown by PLD or sputtering [49]. However, film grown by these deposition techniques have varying degree of crystallinity and non-uniform strain distribution. Which leads to poor OFF/ON resistivity contrast and increases substrate capacitance. Datta et al. demonstrate a wafer scale [79] $\mathrm{VO}_{2}$ based device using metal-organic molecular beam epitaxy (MOMBE) grown epi film (35 nm thickness) with thermally triggered resistivity ratio $10^{4}$. The signal line of this CPW series type device consists of 24 parallel channels of $1 \mu \mathrm{m}$ width (effective width $24 \mu \mathrm{m}$ ) and $100 \mathrm{~nm}$ length as shown in Figure 12. For electrically triggered device at elevated temperature $(340 \mathrm{~K})$, in off state (bias current $0 \mathrm{~mA}$ ) the device has flat response till $10 \mathrm{GHz}$ with isolation $\sim 35 \mathrm{~dB}$. On the other hand, in on state (DC bias current $25 \mathrm{~mA}$, Applied Voltage $>\sim 1.1 \mathrm{~V}$ ) device has flat response till $50 \mathrm{GHz}$ with insertion loss of $\sim 0.55 \mathrm{~dB}$. The switch has $\mathrm{C}_{\mathrm{OFF}}$ of $41.6 \mathrm{fF} / \mathrm{mm}$ and $\mathrm{R}_{\mathrm{ON}}$ of $0.146 \Omega$-mm $(6 \Omega)$ with results to an intrinsic $\mathrm{F}_{\mathrm{CO}}$ of $26.5 \mathrm{THz}$. On the other hand, the cut off frequency for a thermally driven $\left(\mathrm{T}_{\text {off }}=298\right.$ and $\left.\mathrm{T}_{\text {on }}=358 \mathrm{~K} / 85^{\circ} \mathrm{C}\right)$ device is evaluated to be $44 \mathrm{THz}$. The device shows excellent linearity with input power swept from $1 \mu \mathrm{W}$ to $15 \mathrm{~mW}$, in the on state $1 \mathrm{~dB}$ compression point is better than $12 \mathrm{dBm}$. The switching delay is found to be less than $25 \mathrm{~ns}$. They also test the reliability of the device by applying $100 \mathrm{kHz}$ pulse of amplitude $2 \mathrm{~V}$ with $20 \%$ duty cycle, only minimal degradation occurred after $680 \mathrm{M}$ cycle and breakdown or device failure never occurred. 


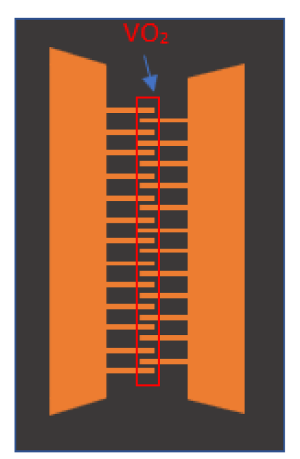

Figure 12. Signal line of CPW switches consist of 24 parallel structure.

\section{Performance Benchmarking of GeTe and $\mathrm{VO}_{2}$}

This section primarily provides one to one comparisons on RF performance parameters associated with these two RF switches at two representative frequencies; $10 \mathrm{GHz}$ and $20 \mathrm{GHz}$; as existing $4 \mathrm{G}$ technology band covers $2-8 \mathrm{GHz}$ and next generation 5G technology extends beyond $26 \mathrm{GHz}$. Device active length directly affects insertion loss of the switch and it increases with device length if all the other material and design parameters are kept same.

Figures 13 and 14 depict the progress in insertion loss and isolation associated with GeTe and $\mathrm{VO}_{2}$ based RF switches over the years. Still there is no linear improvement of performance metrics over the year as shown in the figures. This is because different groups used different design parameters and actuation methods. This motivates us to investigate the correlation between RF performance metrics with respect to design parameters (lengths and volumes).

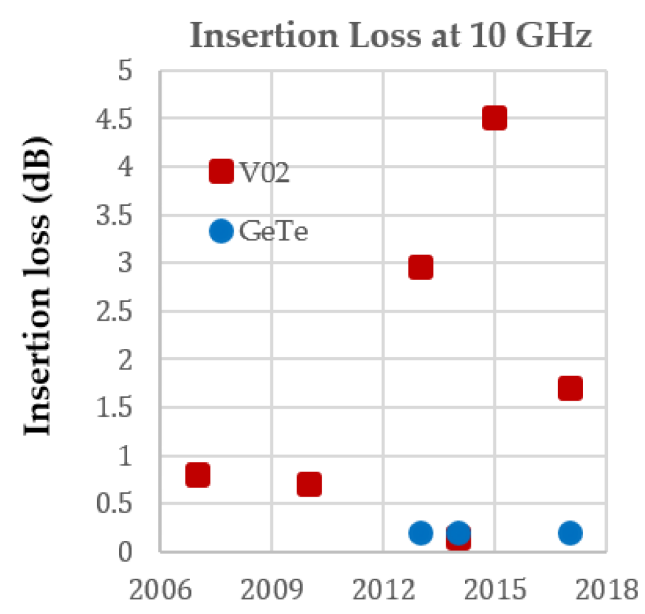

Timeline (Year)

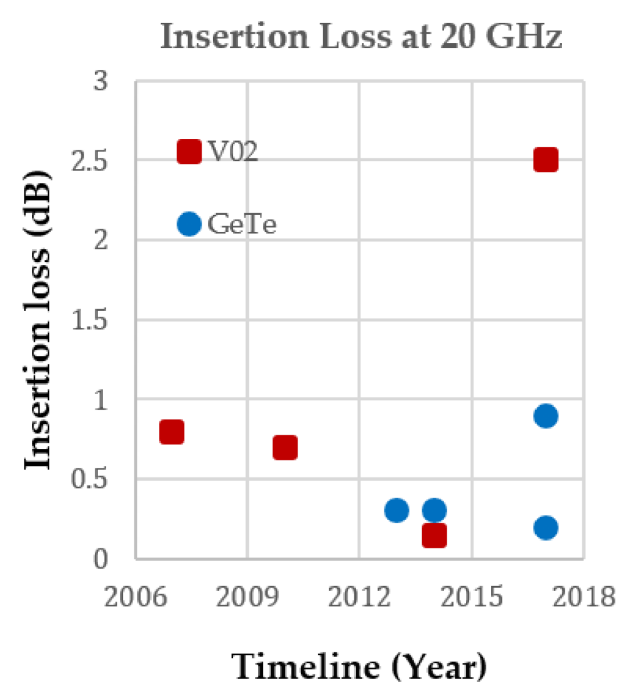

(b)

Figure 13. Progress in insertion loss associated with $\mathrm{GeTe}$ and $\mathrm{VO}_{2}$ based switches over the years. (a) Insertion loss at $10 \mathrm{GHz}$; (b) Insertion loss at $20 \mathrm{GHz}$. 


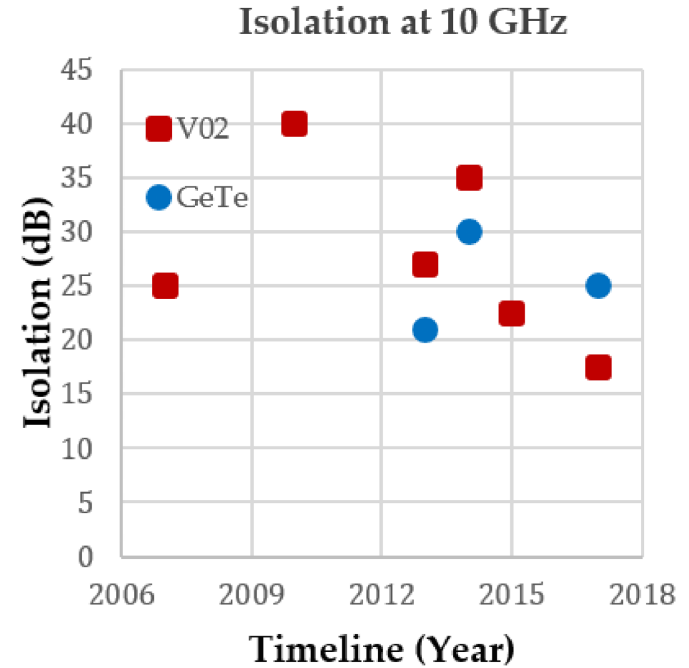

(a)

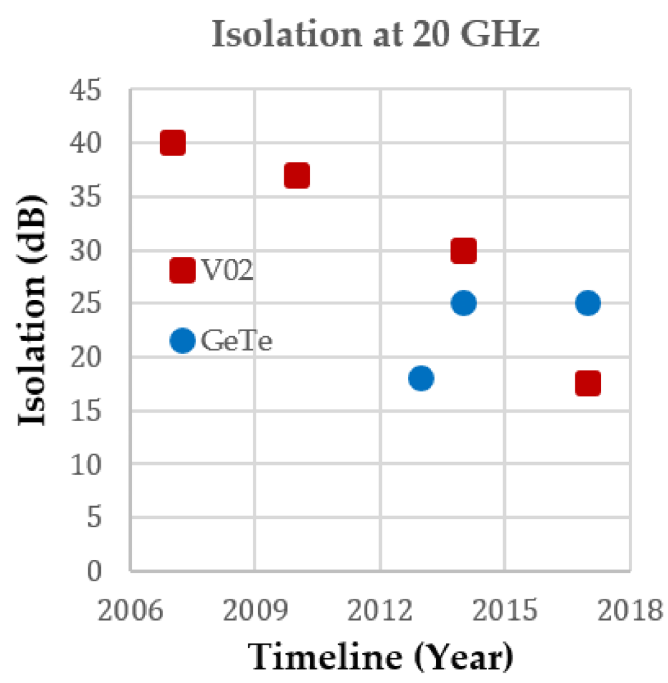

(b)

Figure 14. Progress in isolation associated with $\mathrm{GeTe}$ and $\mathrm{VO}_{2}$ based switches over the years. (a) Isolation at $10 \mathrm{GHz}$; (b) Isolation at $20 \mathrm{GHz}$.

Figures 15 and 16 show insertion losses associated with each of the switching element's lengths and volumes based on the reported values at the frequency of $10 \mathrm{GHz}$ and $20 \mathrm{GHz}$. While shunt type $\mathrm{VO}_{2}$ devices show lower insertion loss (less than $\sim 1 \mathrm{~dB}$ ), series type CPW devices show insertion loss above $\sim 3 \mathrm{~dB}$. On the other hand, GeTe are mostly series type, which have demonstrated insertion loss lower than $\sim 1 \mathrm{~dB}$. Moreover, their insertion losses decrease up to $0.2 \mathrm{~dB}$ as the device active lengths decrease as shown in the inlet of the Figure 15. It is evident that for series type switches with CPW configuration, insertion loss in GeTe based devices are lower than that of $\mathrm{VO}_{2}$ based devices. This might be attributed to the lower resistivity of GeTe compared to $\mathrm{VO}_{2}$.

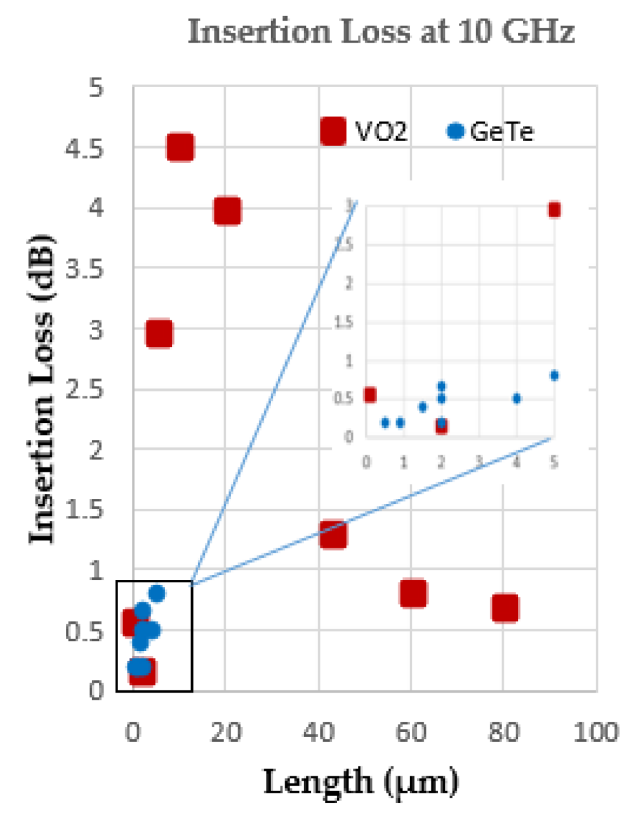

(a)

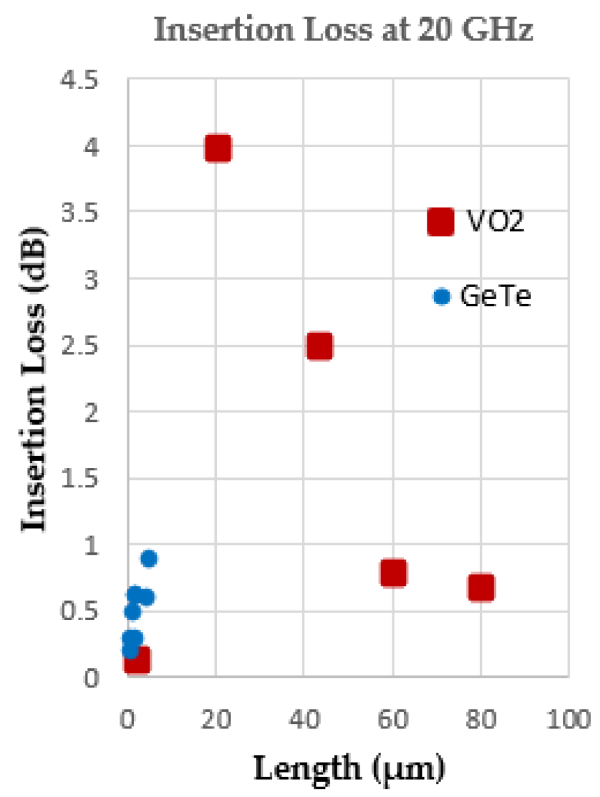

(b)

Figure 15. Insertion losses associated with each reported device active lengths. (a) Insertion loss at $10 \mathrm{GHz}$; (b) Insertion loss at $20 \mathrm{GHz}$. 


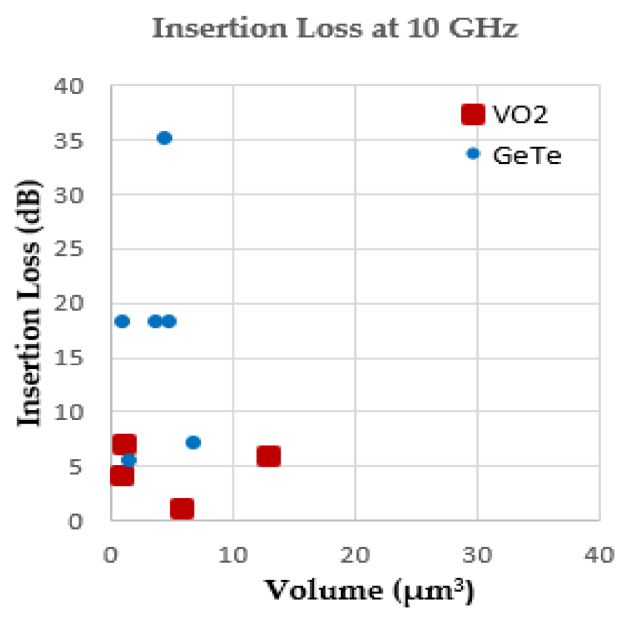

(a)

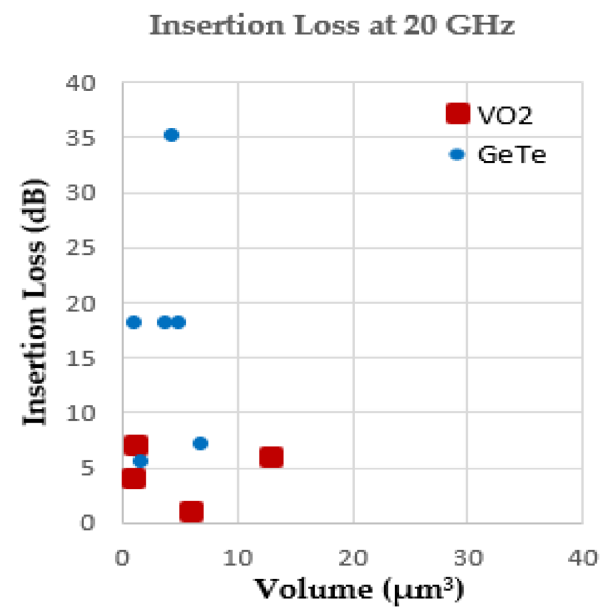

(b)

Figure 16. Insertion losses associated with each reported active volume of the device. (a) Insertion loss at $10 \mathrm{GHz}$; (b) Insertion loss at $20 \mathrm{GHz}$

We also compared the reported isolation between $\mathrm{GeTe}$ and $\mathrm{VO}_{2}$ devices at the same two representative frequency. Figures 17 and 18 depicts that the isolation of $\mathrm{VO}_{2}$ device extends from 17.5 to $40 \mathrm{~dB}$, whereas GeTe shows isolation approximately $12 \mathrm{~dB}$ to $30 \mathrm{~dB}$ at $10 \mathrm{GHz}$. At smaller length, $\mathrm{VO}_{2}$ shows better signal isolation than GeTe, as the off state capacitance of $\mathrm{VO}_{2}$ is lower than GeTe [79]. However, the lower OFF state capacitance of $\mathrm{VO}_{2}$ arises due to its, lower dielectric constant.

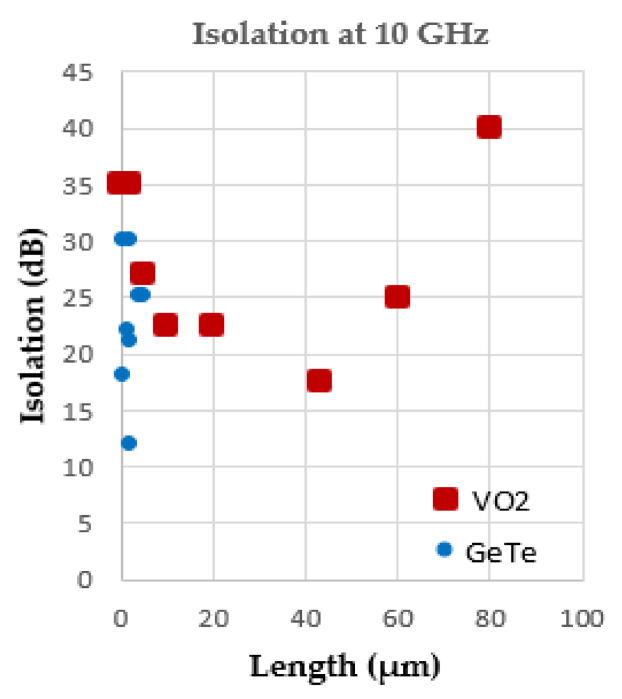

(a)

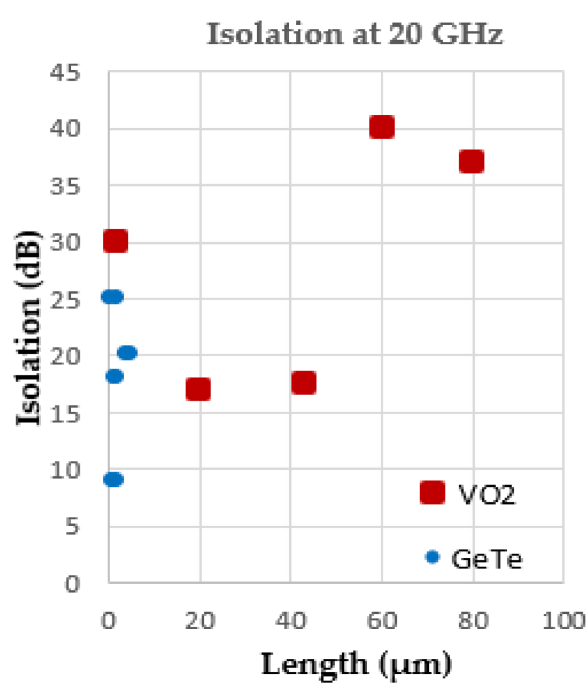

(b)

Figure 17. Isolation losses associated with each reported length of the device. (a) Isolation at $10 \mathrm{GHz}$; (b) Isolation at $20 \mathrm{GHz}$. 


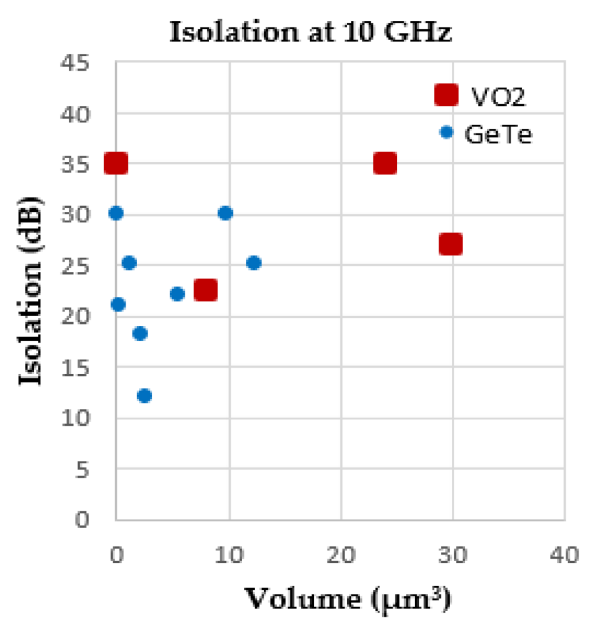

(a)

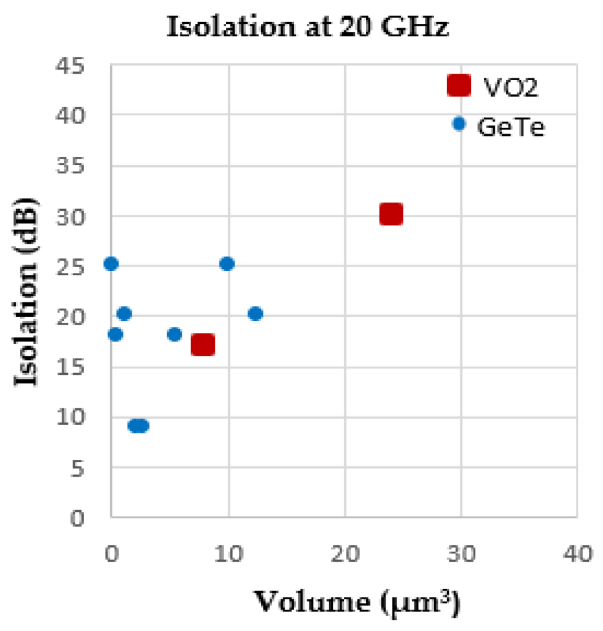

(b)

Figure 18. Isolation associated with each reported volume of the device. (a) Isolation at $10 \mathrm{GHz}$; (b) Isolation at $20 \mathrm{GHz}$.

$\mathrm{VO}_{2}$ has very sharp and fast metal-insulator transition at the nanosecond scale [49], whereas GeTe transition is relatively slow, in the range of $\mu$ s. In addition, GeTe requires longer activation pulse to convert the phase from amorphous to crystalline, but the reverse transition needs much faster. So, the overall speed depends of the crystallization time of the material, which on the order of 10's of $\mu \mathrm{s}$. Figure 19a shows the relation between switching time and volume of the active part of the device. It's obvious that devices with smaller volumes switch faster as less material must be transitioned. This is also evident by the reported data as depicted the Figure 19a. The figure of merit, $\left(\mathrm{F}_{\mathrm{CO}}=\frac{1}{2 \pi * R_{o n} C_{o f f}}\right)$ is an important parameter for RF applications. It can also be defined as the cut-off frequency of the device which dictates the upper limit of operation frequency of a RF switch. The reported cut-off frequency for $\mathrm{VO}_{2}$ based devices range from 2 to $40 \mathrm{THz}$, whereas GeTe shows in the range of $1 \mathrm{THz}$ to $17 \mathrm{THz}$. Most of the reported work reveals that $\mathrm{VO}_{2}$ has got the trends to have higher cut-off frequency (lower values of $R_{o n} C_{o f f}$ ). This is also evident from Figure 19b.

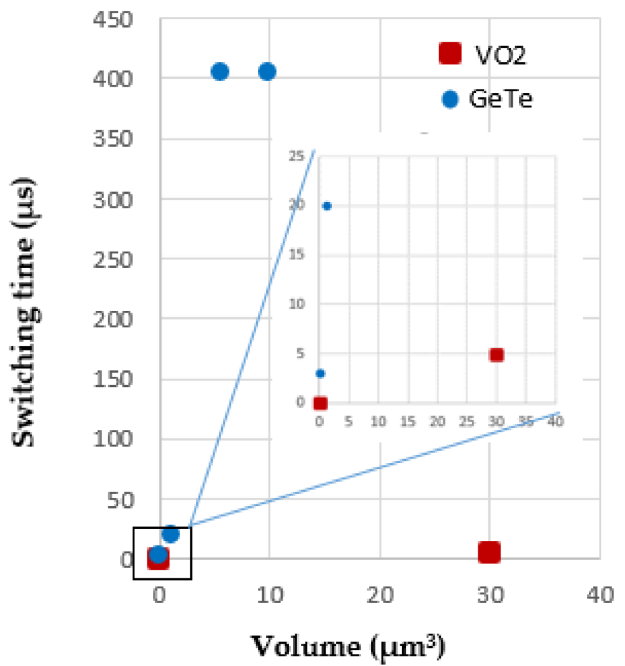

(a)

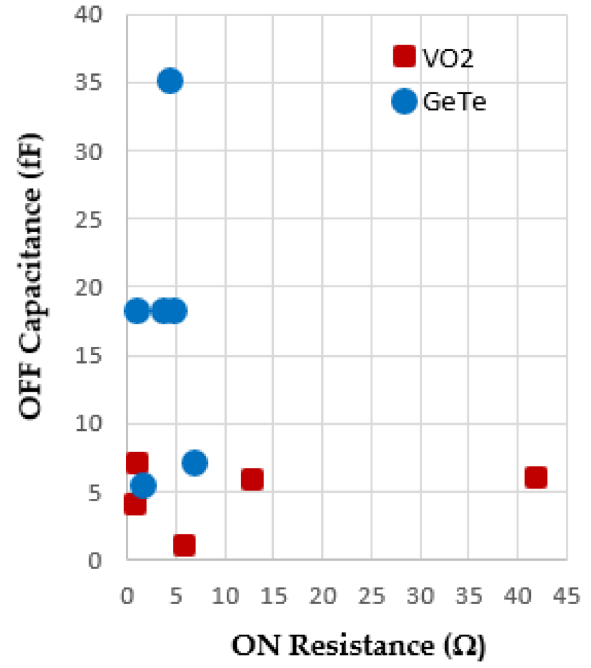

(b)

Figure 19. (a) Switching time associated with reported volume of the devices; (b) OFF capacitance vs. ON resistance. 
Reliability is one of the important parameters for a RF switch to be commercialized which has not been well addressed yet and is still an open question for the both categories of devices. Only few works have been reported in the literature. For GeTe devices maximum reported life cycles is 10,000 [27]. Crunteanu et al. demonstrated methodical reliability analysis for $\mathrm{VO}_{2}$ devices [78]. Their device sustained up to 260 million cycles without any degradations. Recently Madan et al. showed their reliability of the device up to 680 million cycles with no breakdown. Although $\mathrm{VO}_{2}$ has better reliability, but still extensive analysis is needed to establish the reliability.

In addition to scattering parameters, speed and reliability; linearity, power consumptions and power handling capability are also important performance metrics for a RF switch. Linearity is one of the important parameters to evaluate phase and frequency distortions. It is reported that GeTe based switches show good linear characteristics which is evident from its reported third order power intercept values (varies $\sim 27 \mathrm{dBm}$ to $55 \mathrm{dBm}$ ) [24-33]. Ha reported that at high bias current, $\mathrm{VO}_{2}$ also shows very good linear response till $27 \mathrm{dBm}$ power [49]. The average group delay is found to be $2.9 \mathrm{ps}$ up to $40 \mathrm{GHz}$ as reported by Lee [67] which indicates broadband stability of $\mathrm{VO}_{2}$ switches. Madan demonstrates that output third order intercept is of $>44 \mathrm{dBm}$ [79]. Based on these reported values, it can be said that the both types of devices have similar linear characteristics. Maximum reported power handling capability of GeTe is $\sim 3 \mathrm{~W}$ and for $\mathrm{VO}_{2}$ it is $0.5 \mathrm{~W}$. In terms of power consumption, $\mathrm{VO}_{2}$ consumes 10's of $\mathrm{mW}$ of continuous power [32,62], whereas as GeTe is a bi-stable device, it only consumes power during transitions. Table 1 presents the best reported values for each RF performance parameter for GeTe, $\mathrm{VO}_{2}$ and conventional MEMS RF switches irrespective of growth process, design, device geometry and fabrication.

Table 1. Reported best values for each RF performance parameter irrespective of growth process, design, device geometry and fabrication.

\begin{tabular}{cccc}
\hline Performance Parameters & GeTe & VO $_{2}$ & MEMS \\
\hline Favorable Growth Process & Sputtering/PLD & PLD/Sputtering & Standard MEMS process \\
ON Resistance $(\Omega)$ & $0.6[25]$ (series) & 1 (shunt) 6 (Series) $[67,79]$ & $<1[80]$ \\
C $(\mathrm{OFF}(\mathrm{fF})$ & $5.4[33]$ & $6[47]$ & $2-10[80]$ \\
Figures of Merit $(\mathrm{FOM})(\mathrm{THz})$ & $17[33]$ & $18[67]$ & $10-20[81]$ \\
Insertion Loss $(\mathrm{dB})$ & $0.1[30]$ & $0.7[61]$ & $0.2[82]$ \\
Isolation $(\mathrm{dB})$ & $30[30]$ & $40[67]$ & $25[83]$ \\
Switching Speed & $20 \mu \mathrm{s}[25]$ & $25 \mathrm{~ns}[79]$ & $25 \mu \mathrm{s}[83]$ \\
Reliability & $10,000[27]$ & $260 \mathrm{M}[47]$ & $5 \mathrm{~W}[82]$ \\
Power Handling Capability & $3 \mathrm{~W}[30]$ & $2 \mathrm{~W}[47]$ & $150 \mu \mathrm{m}[83]$ \\
Length & $800 \mathrm{~nm}-5 \mu \mathrm{m}[23-33]$ & $100 \mathrm{~nm}-500 \mu \mathrm{m}[47,61,67,79]$ & Extremely High \\
OFF/ON Resistance Ratio & $\sim 10^{3}-10^{6}[23-33]$ & $\sim 10^{3}-10^{5}[47,61,67,79]$ & \\
\hline
\end{tabular}

\section{Discussion}

Both $\mathrm{VO}_{2}$ and GeTe exhibit promising RF properties in terms of fast switching speed and high isolation over broad frequency range compared to conventional MEMS switches. These devices also have much higher cut-off frequency and linearity compared to solid state switches. Low cost, simple fabrication and easy integration with standard CMOS processes make these materials very appealing to the RF community although reliability, power handling capability, power consumptions have not yet been well addressed.

The reliability of GeTe based switches mostly depend on the thermal breakdown of heating materials and reliable phase transitions of GeTe layer. Thermal breakdown in heating materials occurs due to the stress generated by current/voltage pulse whereas the phase transition in GeTe film fails due to material fatigue and oxidation and impurity introduction. Hence, the proper selection of heating materials for thermal actuation and patterning of a quality GeTe film as an active layer are of paramount in importance for designing a robust and reliable GeTe based RF switch. In GeTe based switches, two types of thermal actuation mechanisms; direct and indirect heating are utilized [24-34]. In direct heating mechanism, it is found that device shows better linearity and 
power handling capability compared to its counterpart, however, it still requires external RF choke or impedance matching circuit to effectively deliver the power into the device which ultimately increases the device size. On the other hand, greater isolation between DC and RF signal and simpler fabrication process make the indirect heating schemes most attractive thermal actuation method to the research community nowadays. But here care must be taken in choosing the heating materials as they must have high temperature thermal stability and greater heat coupling capability to GeTe film. In the literature, silicon-chromium ( $\mathrm{SiCr}$ ), nickel-silicon-chromium (NiSiCr), titanium-nitride(TiN), tungsten (W), titanium tungsten (Ti-W), and so forth, have been reported [24-34] as commonly used heating materials. Apart from this fact, the patterning of a quality GeTe film is also big concern for a process engineer. Based on the literature, lift-off and plasma dry etching are widely used processes for patterning GeTe films. Although the lift off process is somewhat easier than plasma dry etching, however poor GeTe film adhesion with other materials make it rather difficult to successfully process. On the other hand, plasma dry etching is cleaner and residue free than lift-off technique but removal of photoresist after GeTe patterning makes the process more delicate and complicated than lift-off. Moreover, stress induced surface defects, cracking, poor crystallization should also be taken care of at the time of patterning. In conclusion, it can be said that to revolutionize the GeTe based RF switching technology for real industry applications, intensive research works are required in terms of material quality of GeTe, device structures and fabrication processes. As the formation of exact crystalline structure is still a big conundrum, knowing the precise atomic structure and formation process of crystalline materials are still unknown. In terms of device structure, most of the works were based on a via structure, however laterally connected heating structure and vertically connected GeTe via, top heater configuration with indirect heating are yet to be explored. In addition, optimization in phase transition temperature and phase transition speed through the introduction of doping elements, impurities and defects have not been explored yet. Obviously, more examinations to resolve the above issues will further advance the ongoing development of phase-change RF switching technology.

Device geometry for $\mathrm{VO}_{2}$ device are usually larger than GeTe device. So, there are lots of room for miniaturization for $\mathrm{VO}_{2}$ based devices, which will improve some of the performance parameter, specially switching speed and insertion loss. With careful design and fabrication technique one can minimize parasitic with will bring over all better performance Most of the RF devices demonstrated so far are $\mathrm{CPW}$ structure. Using other alternative structures like inverted microstrip line may give superior performance as Hillman et al. [65] demonstrated ultra-low loss switch with insertion loss $0.15 \mathrm{~dB}$ and cuff-off frequency of $40 \mathrm{THz}$. However, these may bring additional fabrication complexity. Pan et al. [66] implemented $\mathrm{SiO}_{2}$ as a passivation layer for an integrated heater, which degraded RF performance. An alternative may be to use a low temperature passivation layer to get better results. Most of the electrically triggered $\mathrm{VO}_{2}$ devices are driven by joule heating. Three terminal FET type RF devices have not yet been demonstrated and may have faster switching speeds since joule heating is not required [73]. Introducing doping and interfacial strain changes the resistivity contrast, transition temperature and/or transition electric field $[84,85]$. Even near room temperature transition is possible by engineering the interfacial strain [85]. In this way, low power switching can be achieved. In addition to that playing with these parameters may improve overall RF performance. RF power itself make can trigger the MIT in $\mathrm{VO}_{2}$. Only a few works have been demonstrated in this area [86-88]. Sieu D. Ha implemented RF triggered CPW switches [86] at $10 \mathrm{GHz}$ and found $21 \mathrm{~dB}$ drop in transmission with $\sim 25 \mathrm{dBm}$ power (less than $0.5 \mathrm{~W}$ ).

\section{Conclusions}

This review summarizes the progress in $\mathrm{GeTe}$ and $\mathrm{VO}_{2}$ based $\mathrm{RF}$ switches over the past decade. It provides insight into the relative advantages and disadvantages of both type of the devices for DC and RF applications. The essential design aspects associated with the DC and RF characteristics of these switches have been reviewed and discussed. From the reported works, it is clear that the GeTe based RF switches have lower insertion loss and low power consumption than $\mathrm{VO}_{2}$ based devices. 
On the contrary, $\mathrm{VO}_{2}$ switches outperform GeTe in terms of speed and reliability. There are myriad of materials and/or material compositions which exhibit phase change and metal insulator transition properties with varying degrees of $\mathrm{OFF} / \mathrm{ON}$ resistivity contrast. Intrinsic fast switching capabilities associated with MIT materials and latching (bi-stability) properties associated with PCM may facilitate transformative RF application with new functionality and superior performance. Still there is plenty of room for improvements of switching speed, scattering parameters, reliability in both categories of devices. Optimization in growth, design, and fabrication will leverage in harnessing the full potentials of these materials with respect to the conventional MEMS and solid states switches. At this early stage, it is difficult to determine which material is best suited for future RF applications with the limited number of demonstrated works.

Author Contributions: Protap Mahanta compiled and edited the phase change materials (PCM) portion of the manuscript. M.M. compiled and edited the metal insulator transition (MIT) materials portion of the manuscript. R.A.C., Jr. conceived the original research idea, mentored the graduate student project, and edited the final manuscript.

Funding: This research received no external funding.

Acknowledgments: The authors thank Dushyant Tomer for his technical assistance and administrative support.

Conflicts of Interest: The authors declare no conflict of interest.

\section{References}

1. Wang, M.; Lin, F.; Rais-Zadeh, M. Need a Change? Try GeTe: A Reconfigurable Filter Using Germanium Telluride Phase Change RF Switches. IEEE Microw. Mag. 2016, 17, 70-79. [CrossRef]

2. Rais-Zadeh, M.; Wang, M. Advanced reconfigurable RF/microwave electronics. In Proceedings of the 2017 IEEE Radio and Wireless Symposium (RWS), Phoenix, AZ, USA, 15-18 January 2017; pp. 13-15.

3. Ha, S.D.; Zhou, Y.; Duwel, A.E.; White, D.W.; Ramanathan, S. Quick switch: Strongly correlated electronic phase transition systems for cutting-edge microwave devices. IEEE Microw. Mag. 2014, 15, 32-44. [CrossRef]

4. Wang, M.; Rais-Zadeh, M. Development and evaluation of germanium telluride phase change material based ohmic switches for RF applications. J. Micromech. Microeng. 2016, 27, 013001. [CrossRef]

5. Borodulin, P.; El-Hinnawy, N.; Padilla, C.R.; Ezis, A.; King, M.R.; Johnson, D.R.; Nichols, D.T.; Young, R.M. Recent advances in fabrication and characterization of GeTe-based phase-change RF switches and MMICs. In Proceedings of the 2017 IEEE MTT-S International InMicrowave Symposium (IMS), Honololu, HI, USA, 4-9 June 2017; pp. 285-288.

6. Yamada, N.; Ohno, E.; Akahira, N.; Nishiuchi, K.I.; Nagata, K.I.; Takao, M. High speed overwritable phase change optical disk material. Jpn. J. Appl. Phys. 1987, 26, 61. [CrossRef]

7. Raoux, S.; Wełnic, W.; Ielmini, D. Phase change materials and their application to nonvolatile memories. Chem. Rev. 2009, 110, 240-267. [CrossRef] [PubMed]

8. Raoux, S. Phase change materials. Annu. Rev. Mater. Res. 2009, 39, 25-48. [CrossRef]

9. Siegrist, T.; Merkelbach, P.; Wuttig, M. Phase change materials: Challenges on the path to a universal storage device. Annu. Rev. Condens. Matter Phys. 2012, 3, 215-237. [CrossRef]

10. Tomer, D.; Coutu, R.A. A Phase Change Material for Reconfigurable Circuit Applications. Appl. Sci. 2018, 8, 130. [CrossRef]

11. Champlain, J.G.; Ruppalt, L.B.; Guyette, A.C.; El-Hinnawy, N.; Borodulin, P.; Jones, E.; Young, R.M.; Nichols, D. Examination of the temperature dependent electronic behavior of GeTe for switching applications. J. Appl. Phys. 2016, 119, 244501. [CrossRef]

12. Raoux, S.; Muñoz, B.; Cheng, H.Y.; Jordan-Sweet, J.L. Phase transitions in Ge-Te phase change materials studied by time-resolved x-ray diffraction. Appl. Phys. Lett. 2009, 95, 143118. [CrossRef]

13. Raoux, S.; Cheng, H.-Y.; Muñoz, B.; Jordan-Sweet, J.L. Crystallization characteristics of Ge-Sb and Ge-Te phase change materials. Proc. EPCOS 2009, 91-98. [CrossRef]

14. Choi, Y.F. Phase-change materials: Trends and prospects. In ECI Workshop; Lehigh University: Bethlehem, PA, USA, 2013.

15. Wang, M. Phase Change Material Based Ohmic Switches for Reconfigurable RF Applications. Ph.D. Thesis, University of Michigan, Ann Arbor, MI, USA, 2017. 
16. Rossnagel, S.M. Directional and ionized physical vapor deposition for microelectronics applications. J. Vac. Sci. Technol. B 1998, 16, 2585-2608. [CrossRef]

17. Sun, X. Phase Transformations and Switching of Chalcogenide Phase-change Material Films Prepared by Pulsed Laser Deposition. Available online: http:/ / www.qucosa.de/fileadmin/data/qucosa/documents / 22476/Dissertation_Sun_final\%20version.pdf (accessed on 4 May 2018).

18. Chrisey, D.B.; Hubler, G.K. (Eds.) Pulsed Laser Deposition of Thin Films; J. Wiley: New York, NY, USA, 1994.

19. Kim, R.Y.; Kim, H.G.; Yoon, S.G. Structural properties of $\mathrm{Ge}_{2} \mathrm{Sb}_{2} \mathrm{Te}_{5}$ thin films by metal organic chemical vapor deposition for phase change memory applications. Appl. Phys. Lett. 2006, 89, 102107. [CrossRef]

20. Kim, R.Y.; Kim, H.G.; Yoon, S.G. Characterization of $\mathrm{Ge}_{1-\mathrm{x}} \mathrm{Te}_{\mathrm{x}}$ Chalcogenide Thin Films Deposited by MOCVD for Phase Change Memory Applications. J. Electrochem. Soc. 2008, 155, D137-D140. [CrossRef]

21. Chen, P.S.; Hunks, W.J.; Stender, M.; Chen, T.; Stauf, G.T.; Xu, C.; Roeder, J.F. CVD of amorphous GeTe thin films. MRS Online Proc. Libr. Arch. 2008, 1071. [CrossRef]

22. Lee, J.I.; Park, H.; Cho, S.L.; Park, Y.L.; Bae, B.J.; Park, J.H.; Park, J.S.; An, H.G.; Bae, J.S.; Ahn, D.H.; et al. Highly scalable phase change memory with CVD GeSbTe for sub $50 \mathrm{~nm}$ generation. In Proceedings of the 2007 IEEE Symposium on VLSI Technology, Kyoto, Japan, 12-14 June 2007; pp. 102-103.

23. Chen, K.N.; Krusin-Elbaum, L.; Newns, D.M.; Elmegreen, B.G.; Cheek, R.; Rana, N.; Young, A.M.; Koester, S.J.; Lam, C. Programmable via using indirectly heated phase-change switch for reconfigurable logic applications. IEEE Electron Device Lett. 2008, 29, 131-133. [CrossRef]

24. Lo, H.; Chua, E.; Huang, J.C.; Tan, C.C.; Wen, C.Y.; Zhao, R.; Shi, L.; Chong, C.T.; Paramesh, J.; Schlesinger, T.E.; et al. Three-terminal probe reconfigurable phase-change material switches. IEEE Trans. Electron Devices 2010, 57, 312-320. [CrossRef]

25. Chua, E.K.; Shi, L.P.; Zhao, R.; Lim, K.G.; Chong, T.C.; Schlesinger, T.E.; Bain, J.A. Low resistance, high dynamic range reconfigurable phase change switch for radio frequency applications. Appl. Phys. Lett. 2010, 97, 183506. [CrossRef]

26. Shim, Y.; Hummel, G.; Rais-Zadeh, M. RF switches using phase change materials. In Proceedings of the 2013 IEEE 26th International Conference on Micro Electro Mechanical Systems (MEMS), Taipei, Taiwan, 20-24 January 2013; pp. 237-240.

27. El-Hinnawy, N.; Borodulin, P.; Wagner, B.; King, M.R.; Mason, J.S.; Jones, E.B.; McLaughlin, S.; Veliadis, V.; Snook, M.; Sherwin, M.E.; et al. A four-terminal, inline, chalcogenide phase-change RF switch using an independent resistive heater for thermal actuation. IEEE Electron Device Lett. 2013, 34, 1313-1315. [CrossRef]

28. El-Hinnawy, N.; Borodulin, P.; Wagner, B.P.; King, M.R.; Mason, J.S.; Jones, E.B.; Veliadis, V.; Howell, R.S.; Young, R.M.; Lee, M.J. A 7.3 THz cut-off frequency, inline, chalcogenide phase-change RF switch using an independent resistive heater for thermal actuation. In Proceedings of the Compound Semiconductor Integrated Circuit Symposium (CSICS), Monterey, CA, USA, 13-16 October 2013; pp. 1-4.

29. Wang, M.; Shim, Y.; Rais-Zadeh, M. A low-loss directly heated two-port RF phase change switch. IEEE Electron Device Lett. 2014, 35, 491-493. [CrossRef]

30. Wang, M.; Rais-Zadeh, M. Directly heated four-terminal phase change switches. In Proceedings of the Microwave Symposium (IMS), 2014 IEEE MTT-S International 2014, Tampa, FL, USA, 1-6 June 2014; pp. 1-4.

31. Moon, J.S.; Seo, H.C.; Le, D. Development toward high-power sub-1-ohm DC-67 GHz RF switches using phase change materials for reconfigurable RF front-end. In Proceedings of the Microwave Symposium (IMS), 2014 IEEE MTT-S International 2014, Tampa, FL, USA, 1-6 June 2014; pp. 1-3.

32. Moon, J.S.; Seo, H.C.; Le, D.; Fung, H.; Schmitz, A.; Oh, T.; Kim, S.; Son, K.A.; Zehnder, D.; Yang, B. 11 $\mathrm{THz}$ figure-of-merit phase-change RF switches for reconfigurable wireless front-ends. In Proceedings of the Microwave Symposium (IMS), 2015 IEEE MTT-S International 2015, Phoenix, AZ, USA, 17-22 May 2015; pp. 1-4.

33. Ghalem, A.; Hariri, A.; Guines, C.; Passerieux, D.; Huitema, L.; Blondy, P.; Crunteanu, A. Arrays of GeTe electrically activated RF switches. In Proceedings of the Advanced Materials and Processes for RF and THz Applications (IMWS-AMP), 2017 IEEE MTT-S International Microwave Workshop Serie, Pavia, Italy, 20-22 September 2017; pp. 1-3.

34. Léon, A.; Saint-Patrice, D.; Castellani, N.; Navarro, G.; Puyal, V.; Reig, B.; Podevin, F.; Ferrari, P.; Perret, E. In-depth characterization of the structural phase change of Germanium Telluride for RF switches. In Proceedings of the Advanced Materials and Processes for RF and THz Applications (IMWS-AMP), 2017 IEEE MTT-S International Microwave Workshop Series, Pavia, Italy, 20-22 September 2017; pp. 1-3. 
35. Morin, F.J. Oxides which show a metal-to-insulator transition at the Neel temperature. Phys. Rev. Lett. 1959, 3, 34. [CrossRef]

36. Goodenough, J.B. Anomalous properties of the vanadium oxides. Annu. Rev. Mater. Sci. 1971, 1, 101-138. [CrossRef]

37. Tokura, Y. Correlated-electron physics in transition-metal oxides. Phys. Today 2003, 56, 50-55. [CrossRef]

38. Stefanovich, G.; Pergament, A.; Stefanovich, D. Electrical switching and Mott transition in $\mathrm{VO}_{2}$. J. Phys. Condens. Matter 2000, 12, 8837. [CrossRef]

39. Yang, Z.; Ko, C.; Ramanathan, S. Oxide electronics utilizing ultrafast metal-insulator transitions. Annu. Rev. Mater. Res. 2011, 41, 337-367. [CrossRef]

40. Cavalleri, A.; Dekorsy, T.; Chong, H.H.; Kieffer, J.C.; Schoenlein, R.W. Evidence for a structurally-driven insulator-to-metal transition in $\mathrm{VO}_{2}$ : A view from the ultrafast timescale. Phys. Rev. B 2004, 70, 161102. [CrossRef]

41. Qazilbash, M.M.; Brehm, M.; Chae, B.G.; Ho, P.C.; Andreev, G.O.; Kim, B.J.; Yun, S.J.; Balatsky, A.V.; Maple, M.B.; Keilmann, F.; et al. Mott transition in $\mathrm{VO}_{2}$ revealed by infrared spectroscopy and nano-imaging. Science 2007, 318, 1750-1753. [CrossRef] [PubMed]

42. Qazilbash, M.M.; Tripathi, A.; Schafgans, A.A.; Kim, B.J.; Kim, H.T.; Cai, Z.; Holt, M.V.; Maser, J.M.; Keilmann, F.; Shpyrko, O.G.; et al. Nanoscale imaging of the electronic and structural transitions in vanadium dioxide. Phys. Rev. B 2011, 83, 165108. [CrossRef]

43. Martens, K.; Radu, I.P.; Mertens, S.; Shi, X.; Nyns, L.; Cosemans, S.; Favia, P.; Bender, H.; Conard, T.; Schaekers, $\mathrm{M}$.; et al. The $\mathrm{VO}_{2}$ interface, the metal-insulator transition tunnel junction, and the metal-insulator transition switch On-Off resistance. J. Appl. Phys. 2012, 112, 124501. [CrossRef]

44. Cavalleri, A.; Tóth, C.; Siders, C.W.; Squier, J.A.; Ráksi, F.; Forget, P.; Kieffer, J.C. Femtosecond structural dynamics in $\mathrm{VO}_{2}$ during an ultrafast solid-solid phase transition. Phys. Rev. Lett. 2001, 87, 237401. [CrossRef] [PubMed]

45. Kikuzuki, T.; Lippmaa, M. Characterizing a strain-driven phase transition in $\mathrm{VO}_{2}$. Appl. Phys. Lett. 2010, 96, 132107. [CrossRef]

46. Gupta, A.; Aggarwal, R.; Gupta, P.; Dutta, T.; Narayan, R.J.; Narayan, J. Semiconductor to metal transition characteristics of $\mathrm{VO}_{2}$ thin films grown epitaxially on $\mathrm{Si}$ (001). Appl. Phys. Lett. 2009, 95, 111915. [CrossRef]

47. Wu, B.; Zimmers, A.; Aubin, H.; Ghosh, R.; Liu, Y.; Lopez, R. Electric-field-driven phase transition in vanadium dioxide. Phys. Rev. B 2011, 84, 241410. [CrossRef]

48. Duchene, J.; Terraillon, M.; Pailly, P.; Adam, G. Filamentary Conduction in $\mathrm{VO}_{2}$ Coplanar Thin-Film Devices. Appl. Phys. Lett. 1971, 19, 115-117. [CrossRef]

49. Ha, S.D.; Zhou, Y.; Fisher, C.J.; Ramanathan, S.; Treadway, J.P. Electrical switching dynamics and broadband microwave characteristics of $\mathrm{VO}_{2}$ radio frequency devices. J. Appl. Phys. 2013, 113, 184501. [CrossRef]

50. Sahana, M.B.; Subbanna, G.N.; Shivashankar, S.A. Phase transformation and semiconductor-metal transition in thin films of $\mathrm{VO}_{2}$ deposited by low-pressure metalorganic chemical vapor deposition. J. Appl. Phys. 2002, 92, 6495-6504. [CrossRef]

51. Ruzmetov, D.; Zawilski, K.T.; Narayanamurti, V.; Ramanathan, S. Structure-functional property relationships in rf-sputtered vanadium dioxide thin films. J. Appl. Phys. 2007, 102, 113715. [CrossRef]

52. Narayan, J.; Bhosle, V.M. Phase transition and critical issues in structure-property correlations of vanadium oxide. J. Appl. Phys. 2006, 100, 103524. [CrossRef]

53. Zhang, H.T.; Zhang, L.; Mukherjee, D.; Zheng, Y.X.; Haislmaier, R.C.; Alem, N.; Engel-Herbert, R. Wafer-scale growth of $\mathrm{VO}_{2}$ thin films using a combinatorial approach. Nat. Commun. 2015, 6, 8475. [CrossRef] [PubMed]

54. Zhou, H.; Chisholm, M.F.; Yang, T.H.; Pennycook, S.J.; Narayan, J. Role of interfacial transition layers in $\mathrm{VO}_{2} / \mathrm{Al}_{2} \mathrm{O}_{3}$ heterostructures. J. Appl. Phys. 2011, 110, 073515. [CrossRef]

55. Jeong, J.; Aetukuri, N.; Graf, T.; Schladt, T.D.; Samant, M.G.; Parkin, S.S. Suppression of metal-insulator transition in $\mathrm{VO}_{2}$ by electric field-induced oxygen vacancy formation. Science 2013, 339, 1402-1405. [CrossRef] [PubMed]

56. Sovero, E.; Deakin, D.; Higgins, J.A.; DeNatale, J.F.; Pittman, S. Fast thin film vanadium dioxide microwave switches. In Proceedings of the Gallium Arsenide Integrated Circuit (GaAs IC) Symposium on Technical Digest, New Orleans, LA, USA, 7-10 October 1990; pp. 101-103.

57. Hood, P.J.; DeNatale, J.F. Millimeter-wave dielectric properties of epitaxial vanadium dioxide thin films. J. Appl. Phys. 1991, 70, 376-381. [CrossRef] 
58. Kim, H.T.; Chae, B.G.; Youn, D.H.; Maeng, S.L.; Kim, G.; Kang, K.Y.; Lim, Y.S. Mechanism and observation of Mott transition in $\mathrm{VO}_{2}$-based two-and three-terminal devices. New J. Phys. 2004, 6, 52. [CrossRef]

59. Dragoman, M.; Cismaru, A.; Hartnagel, H.; Plana, R. Reversible metal-semiconductor transitions for microwave switching applications. Appl. Phys. Lett. 2006, 88, 073503. [CrossRef]

60. Dumas-Bouchiat, F.; Champeaux, C.; Catherinot, A.; Crunteanu, A.; Blondy, P. rf-microwave switches based on reversible semiconductor-metal transition of $\mathrm{VO}_{2}$ thin films synthesized by pulsed-laser deposition. Appl. Phys. Lett. 2007, 91, 223505. [CrossRef]

61. Garry, G.; Durand, O.; Lordereau, A. Structural, electrical and optical properties of pulsed laser deposited $\mathrm{VO}_{2}$ thin films on R-and C-sapphire planes. Thin Solid Films 2004, 453, 427-430. [CrossRef]

62. Hillman, C.; Stupar, P.A.; Hacker, J.B.; Griffith, Z.; Field, M.; Rodwell, M. An ultra-low loss millimeter-wave solid state switch technology based on the metal-insulator-transition of vanadium dioxide. In Proceedings of the Microwave Symposium (IMS), 2014 IEEE MTT-S International 2014, Tampa, FL, USA, 1-6 June 2014; pp. 1-4.

63. Pan, K.; Wang, W.; Shin, E.; Freeman, K.; Subramanyam, G. Vanadium oxide thin-film variable resistor-based RF switches. IEEE Trans. Electron Devices 2015, 62, 2959-2965. [CrossRef]

64. Barker, A.S., Jr.; Verleur, H.W.; Guggenheim, H.J. Infrared optical properties of vanadium dioxide above and below the transition temperature. Phys. Rev. Lett. 1966, 17, 1286. [CrossRef]

65. Maurer, D.; Leue, A. Investigation of transition metal oxides by ultrasonic microscopy. Mater. Sci. Eng. A 2004, 370, 440-443. [CrossRef]

66. Aetukuri, N.B.; Gray, A.X.; Drouard, M.; Cossale, M.; Gao, L.; Reid, A.H.; Kukreja, R.; Ohldag, H.; Jenkins, C.A.; Arenholz, E.; et al. Control of the metal-insulator transition in vanadium dioxide by modifying orbital occupancy. Nat. Phys. 2013, 9, 661. [CrossRef]

67. Lee, J.; Lee, D.; Cho, S.J.; Seo, J.H.; Liu, D.; Eom, C.B.; Ma, Z. Epitaxial $\mathrm{VO}_{2}$ thin film-based radio-frequency switches with thermal activation. Appl. Phys. Lett. 2017, 111, 063110. [CrossRef]

68. Lee, D.; Lee, J.; Song, K.; Xue, F.; Choi, S.Y.; Ma, Y.; Podkaminer, J.; Liu, D.; Liu, S.C.; Chung, B.; et al. Sharpened $\mathrm{VO}_{2}$ phase transition via controlled release of epitaxial strain. Nano Lett. 2017, 17, 5614-5619. [CrossRef] [PubMed]

69. Quackenbush, N.F.; Paik, H.; Wahila, M.J.; Sallis, S.; Holtz, M.E.; Huang, X.; Ganose, A.; Morgan, B.J.; Scanlon, D.O.; Gu, Y.; et al. Stability of the M2 phase of vanadium dioxide induced by coherent epitaxial strain. Phys. Rev. B 2016, 94, 085105. [CrossRef]

70. Kim, H.T.; Kim, B.J.; Choi, S.; Chae, B.G.; Lee, Y.W.; Driscoll, T.; Qazilbash, M.M.; Basov, D.N. Electrical oscillations induced by the metal-insulator transition in $\mathrm{VO}_{2}$. J. Appl. Phys. 2010, 107, 023702. [CrossRef]

71. Crunteanu, A.; Givernaud, J.; Leroy, J.; Mardivirin, D.; Champeaux, C.; Orlianges, J.C.; Catherinot, A.; Blondy, P. Voltage-and current-activated metal-insulator transition in $\mathrm{VO}_{2}$-based electrical switches: A lifetime operation analysis. Sci. Technol. Adv. Mater. 2010, 11, 065002. [CrossRef] [PubMed]

72. Guzman, G.; Beteille, F.; Morineau, R.; Livage, J. Electrical switching in $\mathrm{VO}_{2}$ sol-gel films. J. Mater. Chem. 1996, 6, 505-506. [CrossRef]

73. Ilinski, A.; Silva-Andrade, F.; Shadrin, E.; Klimov, V. Variations in optical reflectivity in the semiconductor-metal phase transition of vanadium dioxide. J. Non-crystalline Solids 2004, 338, 266-268. [CrossRef]

74. Sakai, J. High-efficiency voltage oscillation in $\mathrm{VO}_{2}$ planer-type junctions with infinite negative differential resistance. J. Appl. Phys. 2008, 103, 103708. [CrossRef]

75. Leroy, J.; Crunteanu, A.; Bessaudou, A.; Cosset, F.; Champeaux, C.; Orlianges, J.C. High-speed metal-insulator transition in vanadium dioxide films induced by an electrical pulsed voltage over nano-gap electrodes. Appl. Phys. Lett. 2012, 100, 213507. [CrossRef]

76. Zhou, Y.; Chen, X.; Ko, C.; Yang, Z.; Mouli, C.; Ramanathan, S. Voltage-triggered ultrafast phase transition in vanadium dioxide switches. IEEE Electron Device Lett. 2013, 34, 220-222. [CrossRef]

77. Ko, C.; Ramanathan, S. Observation of electric field-assisted phase transition in thin film vanadium oxide in a metal-oxide-semiconductor device geometry. Appl. Phys. Lett. 2008, 93, 252101. [CrossRef]

78. Chae, B.G.; Kim, H.T.; Youn, D.H.; Kang, K.Y. Abrupt metal-insulator transition observed in $\mathrm{VO}_{2}$ thin films induced by a switching voltage pulse. Phys. B Condens. Matter 2005, 369, 76-80. [CrossRef] 
79. Madan, H.; Zhang, H.T.; Jerry, M.; Mukherjee, D.; Alem, N.; Engel-Herbert, R.; Datta, S. 26.5 Terahertz electrically triggered $\mathrm{RF}$ switch on epitaxial $\mathrm{VO}_{2}$-on-Sapphire (VOS) wafer. In Proceedings of the Electron Devices Meeting (IEDM), 2015 IEEE International 2015, Washington, DC, USA, 7-9 December 2015; pp. 3-9.

80. Basu, A.; Adams, G.G.; McGruer, N.E. A review of micro-contact physics, materials, and failure mechanisms in direct-contact RF MEMS switches. J. Micromech. Microeng. 2016, 26, 104004. [CrossRef]

81. Basu, A. An Experimental Investigation of Hot Switching Contact Damage in RF MEMS Switches. Ph.D. Thesis, Northeastern University, Boston, MA, USA, 2013.

82. Patel, C.D.; Rebeiz, G.M. A high power ( $>5 \mathrm{~W})$ temperature stable RF MEMS metal-contact switch with orthogonal anchors and force-enhancing stoppers. In Proceedings of the Microwave Symposium Digest (MTT), 2011 IEEE MTT-S International 2011, Baltimore, MD, USA, 5-10 June 2011; pp. 1-4.

83. Chan, R.; Lesnick, R.; Becher, D.; Feng, M. Low-actuation voltage RF MEMS shunt switch with cold switching lifetime of seven billion cycles. J. Microelectromech. Syst. 2003, 12, 713-719. [CrossRef]

84. Burkhardt, W.; Christmann, T.; Meyer, B.K.; Niessner, W.; Schalch, D.; Scharmann, A. W-and F-doped VO 2 films studied by photoelectron spectrometry. Thin Solid Films 1999, 345, 229-235. [CrossRef]

85. Muraoka, Y.; Hiroi, Z. Metal-insulator transition of $\mathrm{VO}_{2}$ thin films grown on $\mathrm{TiO}_{2}(001)$ and (110) substrates. Appl. Phys. Lett. 2002, 80, 583-585. [CrossRef]

86. Ha, S.D.; Zhou, Y.; Fisher, C.J.; Ramanathan, S.; Treadway, J.P. Abrupt Insertion Loss Drop by RF-Triggering of the Phase Transition in $\mathrm{VO}_{2} \mathrm{CPW}$ Switches. IEEE Microw. Wirel. Compon. Lett. 2014, 24, 575-577. [CrossRef]

87. Givernaud, J.; Crunteanu, A.; Orlianges, J.C.; Pothier, A.; Champeaux, C.; Catherinot, A.; Blondy, P. Microwave power limiting devices based on the semiconductor-metal transition in vanadium-dioxide thin films. IEEE Trans. Microw. Theory Tech. 2010, 58, 2352-2361. [CrossRef]

88. Givernaud, J.; Crunteanu, A.; Pothier, A.; Champeaux, C.; Catherinot, A.; Blondy, P. CPW self-resetting power limiting devices based on microwave power induced semiconductor-metal transition in vanadium dioxide. In Proceedings of the Microwave Symposium Digest, 2009. MTT'09. IEEE MTT-S International 2009, Boston, MA, USA, 7-12 June 2009; pp. 109-112.

(C) 2018 by the authors. Licensee MDPI, Basel, Switzerland. This article is an open access article distributed under the terms and conditions of the Creative Commons Attribution (CC BY) license (http:/ / creativecommons.org/licenses/by/4.0/). 